\title{
The NAC family transcription factor GmNAC42-1 regulates biosynthesis of the anticancer and neuroprotective glyceollins in soybean
}

Md Asraful Jahan', Brianna Harris², Matthew Lowery ${ }^{3}$, Katie Coburn², Aniello M. Infante ${ }^{4}$, Ryan J. Percifield², Amanda G. Ammer ${ }^{5}$ and Nik Kovinich ${ }^{1 *}$ (D)

\begin{abstract}
Background: Glyceollins are isoflavonoid-derived pathogen-inducible defense metabolites (phytoalexins) from soybean (Glycine max L. Merr) that have important roles in providing defense against pathogens. They also have impressive anticancer and neuroprotective activities in mammals. Despite their potential usefulness as therapeutics, glyceollins are not economical to synthesize and are biosynthesized only transiently and in low amounts in response to specific stresses. Engineering the regulation of glyceollin biosynthesis may be a promising approach to enhance their bioproduction, yet the transcription factors (TFs) that regulate their biosynthesis have remained elusive. To address this, we first aimed to identify novel abiotic stresses that enhance or suppress the elicitation of glyceollins and then used a comparative transcriptomics approach to search for TF gene candidates that may positively regulate glyceollin biosynthesis.
\end{abstract}

Results: Acidity stress (pH 3.0 medium) and dehydration exerted prolonged (week-long) inductive or suppressive effects on glyceollin biosynthesis, respectively. RNA-seq found that all known biosynthetic genes were oppositely regulated by acidity stress and dehydration, but known isoflavonoid TFs were not. Systemic acquired resistance (SAR) genes were highly enriched in the geneset. We chose to functionally characterize the NAC (NAM/ATAF1/2/CUC2)-family TF GmNAC42-1 that was annotated as an SAR gene and a homolog of the Arabidopsis thaliana (Arabidopsis) indole alkaloid phytoalexin regulator ANAC042. Overexpressing and silencing GmNAC42-1 in elicited soybean hairy roots dramatically enhanced and suppressed the amounts of glyceollin metabolites and biosynthesis gene mRNAs, respectively. Yet, overexpressing GmNAC42-1 in non-elicited hairy roots failed to stimulate the expressions of all biosynthesis genes. Thus, GmNAC42-1 was necessary but not sufficient to activate all biosynthesis genes on its own, suggesting an important role in the glyceollin gene regulatory network (GRN). The GmNAC42-1 protein directly bound the promoters of biosynthesis genes IFS2 and G4DT in the yeast one-hybrid (Y1H) system.

Conclusions: Acidity stress is a novel elicitor and dehydration is a suppressor of glyceollin biosynthesis. The TF gene GmNAC42-1 is an essential positive regulator of glyceollin biosynthesis. Overexpressing GmNAC42-1 in hairy roots can be used to increase glyceollin yields > 10-fold upon elicitation. Thus, manipulating the expressions of glyceollin TFs is an effective strategy for enhancing the bioproduction of glyceollins in soybean.

Keywords: Phytoalexin, Transcription factor, NAC, Isoflavonoids, Glyceollins

\footnotetext{
* Correspondence: Nikola.Kovinich@mail.wvu.edu

'Division of Plant and Soil Sciences, West Virginia University, Morgantown,

West Virginia 26506, USA

Full list of author information is available at the end of the article
}

(c) The Author(s). 2019 Open Access This article is distributed under the terms of the Creative Commons Attribution 4.0 International License (http://creativecommons.org/licenses/by/4.0/), which permits unrestricted use, distribution, and reproduction in any medium, provided you give appropriate credit to the original author(s) and the source, provide a link to the Creative Commons license, and indicate if changes were made. The Creative Commons Public Domain Dedication waiver (http://creativecommons.org/publicdomain/zero/1.0/) applies to the data made available in this article, unless otherwise stated. 


\section{Background}

In 1939 K.O. Mueller et al. reported that metabolites that were elicited in potato upon inoculation with an incompatible race of Phytophthora infestans subsequently provided resistance to a compatible race [1]. Since then, the pathogen-inducible defense metabolites that have been identified from numerous plant species have collectively been referred to as 'phytoalexins'. Some phytoalexins have essential roles in defending agricultural crops against major pathogens. A classic example is the glyceollins of soybean that provide resistance to the oomycete Phytophthora sojae [2-4]. For decades researchers have studied the genetic regulation of phytoalexin elicitation by pathogens. Efforts have recently focused on identifying the transcription factors (TFs) that activate phytoalexin biosynthesis, a goal that has been confounded by the myriad of plant responses that occur synchronously in response to pathogens. Phytoalexins are biosynthetically diverse among plant species and include the isoflavonoid-derived glyceollins from soybean, the phenylpropanoid stilbenes from grapevine, the phenolic aldehyde gossypol from cotton, the terpenoid momilactones and phytocassanes from rice, and the indole alkaloid camalexin from Arabidopsis [5-10]. Since the TFs that activate the biosynthesis of phytoalexins in different plant species belong to different gene families and/or are non-homologous, for decades an important question has remained whether phytoalexin TFs are as diverse as the biosynthetic pathways that they regulate. Yet, several excellent reviews highlight that phytoalexins share common abiotic elicitors [11-13]. This could suggest conserved regulatory pathways and TFs among plant species despite the biosynthetic heterogeneity of phytoalexins.

Highly conserved abiotic elicitors of phytoalexins include heavy metals, herbicides, and UV irradiation. UV elicits stilbene phytoalexins in grapevine, Cissus Antarctica, and Cannabis sativa [14], the flavonoid and diterpenoid phytoalexins in rice $[15,16]$, camalexin in Arabidopsis [17], and glyceollins in soybean [18]. In rice, loss-of-function mutants of the JA biosynthesis gene allene oxide cyclase (aos) or jasmonic acid-amido synthetase (osjar1-2) resulted in an almost complete loss of sakuranetin elicitation in response to UV [19]. Yet, the diterpenoid phytoalexins of rice were not affected in JA biosynthesis mutants. Copper chloride $\left(\mathrm{CuCl}_{2}\right)$ elicitation of sakuranetin, momilactone, and diterpenoid phytoalexins in rice was dramatically reduced by JA biosynthesis inhibitors [20]. The heavy metal silver nitrate $\left(\mathrm{AgNO}_{3}\right)$ elicited glyceollin accumulation in soybean by reducing its degradation and by enhancing the hydrolysis of isoflavone-glycoside conjugates that compete with glyceollins for the common biosynthetic intermediate daidzein [21]. $\mathrm{AgNO}_{3}$ was shown to antagonize many plant development processes by inhibiting ethylene perception [22]. Yet, glyceollin elicitation by
$\mathrm{AgNO}_{3}$ was largely independent of ethylene signaling [21]. Herbicides such as acifluorfen elicit at least in part via the reactive oxygen species (ROS) signaling pathway(s). The ups1 loss-of-function mutant of Arabidopsis defective in ROS signaling had reduced camalexin levels in response acifluorfen [23]. ups1 also had reduced camalexin levels in response to Pseudomonas syringae and P. syringae pv maculicola (Psm), suggesting a shared biotic and abiotic elicitation pathway. In soybean, treatments with JA, ethylene, P. sojae WGE, or hydroxyl radical (a ROS) were highly effective at priming glyceollin biosynthesis in cells distal to the point of treatment, whereas SA was not [23, 24].

In contrast to the abiotic stresses and signaling molecules that have conserved roles in eliciting phytoalexins in response to abiotic stresses, the TFs found to regulate phytoalexin biosynthesis have varied widely among plant species. GaWRKY1 activated gossypol biosynthesis in cotton [8]. GaWRKY1 transcripts were induced by methyl jasmonate (MeJA) and Verticillium dahlia but not by SA or $\mathrm{H}_{2} \mathrm{O}_{2}$. GaWRKY1 transcripts were co-expressed both spatially and temporally with gossypol biosynthesis genes and GaWRKY1 was able to directly bind the promoter of $(+)$ - $\delta$-cadinene synthase $(C A D 1)$ in the $\mathrm{Y} 1 \mathrm{H}$ system. Another WRKY-family TF, namely AtWRKY33, was identified from Arabidopsis to directly bind and activate the promoter of the camalexin biosynthesis gene PAD3 [25]. WRKY33 transcripts were induced by the ROS-inducing herbicide paraquat, SA, and necrotrophic fungal pathogens [10]. GaWRKY1 and AtWRKY33 were not homologous since the proteins they encode had more than 20 other proteins that were more similar by reciprocal BLASTPs.

The R2R3-type MYB TF genes $V v M Y B 14$ and $V v M Y B 15$ from grapevine were co-induced with stilbene biosynthesis genes in response to UV irradiation, wounding, and the pathogen Plasmopara viticola [26]. The proteins directly bound the promoter of STILBENE SYNTHASE (STS) in transient gene reporter assays using grapevine suspension cells and induced the accumulation of stilbenes when overexpressed in grapevine hairy roots [26]. Homologs of $V v M Y B 14$ and $V v M Y B 15$ in Arabidopsis did not regulate camalexin biosynthesis but rather cold tolerance and defense-induced lignification, respectively [27, 28]. Double and triple mutants of the Arabidopsis R2R3 MYBs AtMYB34, AtMYB51, and AtMYB122 had reduced camalexin levels upon elicitation with $\mathrm{UV}, \mathrm{AgNO}_{3}$, and a PAMP isolated from Pythium aphanidermatum (PaNie) [29]. However, these three MYBs were unable to bind camalexin biosynthesis gene promoters and feeding the triple mutant plant with a biosynthetic intermediate restored camalexin accumulation, suggesting that AtMYB34, AtMYB51, and AtMYB122 did not regulate camalexin biosynthesis directly but rather an upstream process in the elicitation pathway [29]. The constitutive overexpression of the sorghum R2R3 
MYB gene yellow seed (y1) in maize resulted in the ectopic accumulation of 3-deoxyanthocyanidins in vegetative tissues only upon challenge with Colletotrichum graminicola [5]. $V v M Y B 15$ and $V v M Y B 14$ were not homologs of $y 1$ since reciprocal BLASTp's revealed 5-20 proteins that were more similar.

RNAi silencing of the bHLH-family TF gene OsMYC2 from rice almost completely eliminated the elicitation of sakuranetin in response to JA treatment [6]. OsMYC2 directly activated the promoter of a sakuranetin biosynthesis gene by transient transactivation assays in rice leaves [6]. Transcripts of another bHLH TF gene from rice, namely $O s D P F$, were inducible in rice leaves by $\mathrm{UV}$, $\mathrm{CuCl}_{2}$ and blast infection [9]. OsDPF directly activated the promoters of phytocassane and momilactone biosynthesis genes by transient transactivation assays in rice leaves. Overexpressing OsDPF resulted in increased expression of all diterpenoid biosynthetic genes and the accumulation of momilactones and phytocassanes, whereas decreased levels were observed in RNAi knock-down lines. Two homologous JA-inducible bHLHs, TSAR1 and TSAR2, were identified to directly activate triterpene saponin biosynthesis genes in Medicago truncatula [9]. TSAR1 and TSAR2 were not among the top 20 most similar proteins compared to OsDPF or OsMYC2, and OsDPF was only the 10th most similar to OsMYC2.

A NAC-type TF gene, AtANAC042, was identified from Arabidopsis by T-DNA insertion mutagenesis to have reduced levels of camalexin biosynthesis gene expressions and metabolites when elicited with the ROS-inducing herbicide acifluorofen, bacterial flagellin, or A. brassicicola [7]. Bacterial flagellin stimulated the accumulation of AtANACO42 transcripts at the elongation zone of the root (the site of camalexin biosynthesis), and the induction was abolished in the presence of either MeJA, a general kinase inhibitor (K252a), or a $\mathrm{Ca}^{2+}$-chelator (BAPTA).

Collectively, these studies have demonstrated that phytoalexin biosynthetic pathways are regulated by disparate, non-homologous TFs in different plant species, raising the question of whether any TF has a conserved role in regulating the biosynthesis of phytoalexins in plants. Here, we used a comparative transcriptomics approach on soybean that was exposed to novel abiotic stresses and identified a conserved phytoalexin regulator.

\section{Materials and methods Chemicals}

(-)-Glyceollin I was from Dr. Paul Erhardt (University of Toledo). Soybean isoflavonoid standards were purified and characterized according to [21]. Isoflavone standards were from Extrasynthese (France). Solvents were LC-MS grade (Fisher).

\section{Plant materials and growth conditions}

Soybean seeds were obtained from the USDA-GRIN soybean germplasm collection and from Elroy Cober (Agriculture and Agri-Food Canada). Harosoy 63 seeds (16 per batch) were sterilized in $30 \mathrm{~mL}$ of $70 \%$ ethanol, $0.2 \%$ triton X $(v / v)$ for $5 \mathrm{~min}$ on a mixer wheel, rinsed thrice with sterile water, and imbibed overnight. The imbibate was then discarded to remove growth inhibitors and seeds were transferred to water soaked sterile vermiculite $(250 \mathrm{~mL}$ in volume) in $500 \mathrm{~mL}$ beakers. The beaker tops were covered with ring-shaped sterile cheese cloth and covered with plastic wrap to ensure aseptic growth. The cheese cloth permitted passage of air between plastic wrap and the beaker top and the ring shape permitted the passage of light from above the beaker. Seedlings were grown at $22^{\circ} \mathrm{C}$ under a $16 \mathrm{~h}$ photoperiod using

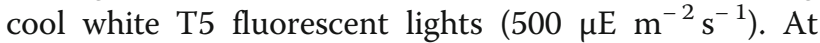
the first trifoliate leaf stage ( $\sim 8$ day old), seedling roots were gently rinsed with sterile water to remove vermiculite and were transferred to stress treatments.

\section{Stress treatments}

For all stress treatments, the roots of five seedlings were wrapped together in a germination paper (Sartorius AG, Göttingen, Germany) saturated with half-strength Murashige and Skoog (MS) medium (pH 5.8) containing vitamins and $1 \%(w / v)$ sucrose unless indicated otherwise. The wrapped seedlings were transferred to a $100 \mathrm{~mL}$ beaker containing $50 \mathrm{~mL}$ of the above medium for the control, cold, heat, wounding and UV-C treatments. Each of the $100 \mathrm{~mL}$ beakers were then placed inside a sterile $500 \mathrm{~mL}$ beaker and the $500 \mathrm{~mL}$ beaker tops were again covered with a ring-shape cut of sterile cheese cloth overlaid with plastic wrap. The volume of the medium in the basin of the 100 $\mathrm{mL}$ beaker was maintained daily for all treatments, with the exception of the dehydration treatment. For dehydration, the medium-saturated germination paper was allowed to dry gradually in the $100 \mathrm{~mL}$ beaker containing no medium. All seedlings were grown under the temperature and lighting conditions listed above unless otherwise indicated. For heat and cold treatments, the $500 \mathrm{~mL}$ beakers were transferred to 37 and $15{ }^{\circ} \mathrm{C}$, respectively. For high carbon stress, the growth medium in the $100 \mathrm{~mL}$ beaker was replaced with $3 \%$ sucrose in water. For flooding, control medium was maintained up to the level of the hypocotyl-root junction throughout the $9 \mathrm{~d}$ treatment. For phosphate deprivation (-P), half-strength MS medium ( $\mathrm{pH} 5.8$ ) that lacked phosphate was used (Caisson Labs, Smithfield, UT). For UV-C treatment, seedlings in beakers were exposed to a $30 \mathrm{~W}$ g30 t8 germicidal light (Philips, NV) every day for $1 \mathrm{~h}$. For acidity stress, seedlings were transferred half-strength MS medium $\mathrm{pH} 3.0$ (acidified with $\mathrm{HCl}$ ).

After $9 \mathrm{~d}$ of treatment (unless indicated otherwise), the five seedlings per treatment were unwrapped and 
separated, flash-frozen in liquid nitrogen, lyophilized to dryness, and individually ground to a fine powder and stored at $-80^{\circ} \mathrm{C}$ for metabolite and RNA extractions. The stored tissue powder was lyophilized again for $1 \mathrm{~h}$ prior to weighing.

For hairy root experiments, only secondary roots that grew to $3-6 \mathrm{~cm}$ on selection media were considered transgenic and were used for WGE treatments. Roots were cut into $1-\mathrm{cm}$ pieces then overlaid with sterile water (mock) or wall glucan elicitor (WGE) that was extracted from $P$. sojae according to [21]. For RNA extraction, $100 \mathrm{mg}$ of fresh tissue was harvested on ice and freeze dried prior to storage at $-80^{\circ} \mathrm{C}$. For metabolite analyses, fresh hairy root tissues $(\sim 100 \mathrm{mg})$ were extracted immediately upon harvesting without lyophilization.

\section{Isoflavonoid analysis}

For analysis of seedlings, lyophilized tissue powder $(12 \mathrm{mg})$ was extracted with $80 \%$ ethanol $\left(10 \mu \mathrm{L} \mathrm{mg}^{-1}\right.$ dry tissue) and isoflavonoid identifications were done by UPLC-PDA-MS ${ }^{\mathrm{n}}$ as indicated in [21]. Four seedlings per treatment were individually extracted for metabolite analysis. Metabolite analyses of pH 3.0 medium, dehydration stress, and control treatments were confirmed by three independent experiments.

Hairy roots were extracted with $80 \%$ ethanol $\left(1 \mu \mathrm{L} \mathrm{mg}^{-1}\right.$ fresh weight, FW) as described [21]. For all hairy root experiments, five biological replicates were analyzed per treatment. Two independent transformation experiments were analyzed per DNA construct. Absolute amounts of isoflavonoids were determined by comparison of the UPLC-PDA peak areas to a concentration curve of purified or authentic standards as described in [21].

\section{RNA extraction and qRT-PCR}

Total RNA was isolated from lyophilized tissue powder using the Spectrum Plant Total RNA Kit (Sigma-Aldrich, St. Louis, MO, USA) as described [21]. Total RNA (500 ng) was treated with DNase I (Amplification grade, Invitrogen, Carlsbad, CA, USA) to remove genomic DNA and cDNA was synthesized using SuperScript II Reverse Transcriptase (Invitrogen). cDNA templates were diluted 4-fold with water and qRT-PCR was conducted as described [21]. All qRT-PCR experiments included four biological replicates and two technical replicates. Primers used in this study are listed in Additional file 1: Table S1.

\section{RNA-seq}

Total RNA was extracted from the powder of individual seedlings as described above. Three individual seedlings per stress treatment and their respective controls were used to make a total of 12 libraries for RNA-seq analysis. RNA samples were sent to the Genomics Core Facility of West Virginia University for library preparation. The quality of each RNA sample was determined using an RNA Nano 6000 Chip and an Agilent 2100 Bioanalyzer (Santa Clara, CA). RNA samples with an Integrity Number (RIN) greater than 8.0 were used to prepare the libraries. Following quantification of RNA using a Qubit fluorometer, libraries were constructed from $750 \mathrm{ng}$ using the mRNA stranded library prep kit (KAPA Biosystems) as per manufacturer's protocol with nine cycles of PCR. The completed cDNA libraries were quantified using a Qubit and pooled in equimolar ratios prior to sequencing at the Marshall University Genomics Core. The $100 \mathrm{bp}$ paired-end reads were generated using a HiSeq1500 system (Illumina). Eight libraries were sequenced per lane in high-output mode.

Data filtering was carried out to eliminate adapter sequences and/or low-quality reads. The quality of raw reads was determined using FastQC software (http://www.bioin formatics.babraham.ac.uk/projects/fastqc/) and clean reads were then mapped/aligned to Glycine max reference genome (Gmax_275_V2.0.fa, https://phytozome.jgi.doe.gov/pz/ portal.html) using STAR RNA-seq aligner [30] with default mode based on the current gene annotation. Only the paired mapped reads were considered for further analyses. Reads were quantified using using featureCounts [31]. Differentially expressed genes (DEGs) were identified using a Negative Binomial Distribution in DESeq2 [32]. Multiple hypothesis correction was conducted with Benjamini Hochberg procedure to get an adjusted $P$ value at 0.05 which decrease the false discovery rate (FDR). Principle component analysis, heatmap and clustering of the samples were done to check the robustness of the analysis. For the identification of gene homologs, genes were considered to be homologous if their predicted protein sequences were the best matches in reciprocal BLASTPs.

\section{Cloning}

The GmNAC42-1 ORF was PCR amplified from the cDNA of Harosoy63 seedlings treated with pH 3.0 medium (9 dat) by the attB Adapter PCR protocol (Invitrogen, Carlsbad, CA) using Phusion polymerase (Thermo Fisher Scientific) and primers (Additional file 1: Table S1). The amplicon was cloned into the donor vector pDONR221 using BP Clonase II (Invitrogen, Carlsbad, CA) and following sequencing was LR recombined downstream of GFP in the pGWB6 vector to assay subcellular localization and downstream of the GAL4 activation domain in the pDEST-GADT7 vector for $\mathrm{Y} 1 \mathrm{H}$. For silencing, a 227-bp region of exon 2 of GmNAC42-1 was amplified from cDNA and BP cloned into pDONR221, which after sequencing was LR subcloned into the RNAi vector pANDA35HK. Hairpin integrations were confirmed by sequencing.

\section{Soybean hairy roots}

Transgenic soybean hairy roots were produced according to [33] with some modifications. Relatively large Williams 
82 soybean seeds without cracks were surface sterilized with $70 \%$ isopropyl alcohol $(\mathrm{v} / \mathrm{v})$ for $30 \mathrm{~s}$ and $10 \% \mathrm{com}$ mercial bleach $(6.0 \%(\mathrm{v} / \mathrm{v})$ sodium hypochlorite) for $5 \mathrm{~min}$ with gentle agitation, then rinsed three times in sterile MilliQ-filtered water (EMD Millipore, MA). Seeds were transferred to germination paper saturated with germination and co-cultivation (GC) medium (half-strength MS salts (Caisson Labs, UT), 1\% sucrose, $\mathrm{pH} 5.8$, and MS vitamins) in a sterile Petri dish and germinated for $3 \mathrm{~d}$ in the dark, then transferred to cool white T5 fluorescent lights $\left(100 \mu \mathrm{E} \mathrm{s}^{-1} \mathrm{~m}^{2}\right)$ at $24^{\circ} \mathrm{C}$, a condition that was used for all subsequent soybean transformation steps.

Following pre-culture on LB-agar plates containing $50 \mathrm{mg} \mathrm{L}^{-1}$ kanamycin and hygromycin, Agrobacterium rhizogenes strain $\mathrm{K} 599$ containing the empty vector or construct DNA were resuspended to an OD600 of $0.5-0.8$ in phosphate buffer $\left(0.01 \mathrm{M} \mathrm{Na}_{2} \mathrm{HPO}_{4}, 0.15 \mathrm{M}\right.$ $\mathrm{NaCl}, \mathrm{pH} 7.5)$ containing $100 \mu \mathrm{M}$ acetosyringone. Cotyledons were gently twisted off of 6-7 d old seedlings. The apical meristem and hypocotyl was excised and several 1 mm-deep cuts were made across the adaxial surface of the cotyledon with a scalpel previously dipped in the Agrobacterium solution. Twenty-four to 36 cotyledons were inoculated per DNA. Cotyledons were placed adaxial-side-down on germination paper saturated with GC medium containing $100 \mu \mathrm{M}$ acetosyringone and co-cultivated for $3 \mathrm{~d}$ at $22^{\circ} \mathrm{C}$ under low light $\left(65 \mu \mathrm{E} \mathrm{s}^{-1} \mathrm{~m}^{2}\right)$ on a $16 \mathrm{~h}$ photoperiod. Cotyledons were then cultured adaxial-side-up on hairy root growth (HRG) medium (half strength MS salts, 3\% sucrose $(w / v) \quad(\mathrm{pH} 5.8)$ with gelzan $\left(2.4 \mathrm{gL}^{-1}\right.$; Sigma-Aldrich, $\mathrm{MO})$, MS vitamins $\left(2.5 \mathrm{~mL} \mathrm{~L}^{-1}\right)$ and timentin $\left(500 \mathrm{mg} \mathrm{L}^{-1}\right)$. Fourteen to $21 \mathrm{~d}$ later, transgenic primary roots with $2-3 \mathrm{~cm}$ secondary roots were transferred to and selected on HRG containing $50 \mathrm{mg} \mathrm{L}^{-1}$ kanamycin and hygromycin. Only secondary roots that grew to 3-6 $\mathrm{cm}$ were considered transgenic and were used for treatments. All hairy root experiments were conducted two times independently, representative results are shown.

\section{Subcellular localization}

Soybean hairy roots transformed with $n G F P-p G W B 6$ or $n G F P-N A C 42-1-p G W B 6$ were harvested and stained with propidium iodide according to the manufacturer's instructions (Sigma-Aldrich, St. Louis, MO, USA). Three-to-four roots per genotype per two independent transformation events were analyzed and a representative result is shown. Confocal images were acquired using a Nikon A1R Si confocal laser with N-SIM-E, a TiE inverted research microscope, and NIS Elements software. Imaging was performed using an Apo oil 60x objective, plus $1.5 \times$ optical zoom, and $6 \times$ digital zoom. Excitation and emission spectra were $488 \mathrm{~nm}$ and 500 $550 \mathrm{~nm}$ for GFP and $488 \mathrm{~nm}$ and $570-620 \mathrm{~nm}$ for propidium iodide, respectively.

\section{Yeast one-hybrid}

G4DT and IFS2 promoter regions 1 and 2 flanked by attL4 and attR1 recombination sites (Additional file 2: Table S2) were synthesized by Genscript (Piscataway, $\mathrm{NJ}$ ) and recombined into the destination vector $\mathrm{pMW \# 2}$ (Addgene, Cambridge, MA) using LR clonase (Invitrogen, Carlsbad, CA). Clones were selected by colony PCR then sequenced. Constructs were linearized by digestion with AflII (Thermo Scientific, Waltham, MA) prior to transformation into yeast strain YM4271 (MATa, ura3-52, his3-200, lys2-801, ade2-101, ade5, trp1-901, leu2-3, 112, tyr1-501, gal4D, gal80D, ade5::hisG) and were selected by growth in dropout medium lacking histidine (SD-His). Bait strains containing genomic integrations were confirmed by colony PCR using a pair of promoter- and genome-specific primers (Additional file 1: Table S1). Bait strains were transformed with pDEST-GADT7 (ABRC, Columbus, $\mathrm{OH}$ ) or with GmNAC42-1-pDEST-GADT7 and transformants were selected on media lacking histidine and leucine (SD-His-Leu) then confirmed by colony PCR. Autoactivation was tested for and positive DNA-protein interactions were determined by growth in SD-His-Leu medium containing increasing concentrations $(5,10,20$, 40 and $60 \mathrm{mM}$ ) of 3-amino-1,2,4-triazole (3-AT; Fisher Scientific, Hampton, NH), as previously described [34]. Three biological replicates are shown, results were confirmed by two independent experiments.

\section{Results}

Novel abiotic stresses that regulate glyceollin biosynthesis To gain insight into how abiotic stresses regulate glyceollin biosynthesis in soybean we first searched for a control growth condition that would allow us to measure the inductive and suppressive effects of abiotic stress treatments on glyceollin biosynthesis. We grew soybean seedlings under two light intensities, 10 and $500 \mu \mathrm{mol} \mathrm{m}^{-2} \mathrm{~s}^{-1}$, which we refer to here as low and high light, respectively. We also compared seedlings grown on soil to those grown in liquid half-strength Murashige and Skoog (MS) medium that can be readily manipulated to provide nutrient and chemical stresses (see Methods). In addition to glyceollins, we also measured the levels of two key biosynthetic intermediates, two additional phytoalexins that have potent anti-pathogenic and/or medicinal activities, and two constitutively biosynthesized isoflavone-glycoside conjugates known to compete with glyceollins for biosynthetic intermediates. Specifically, we measured the levels of glyceollin I, glyceollin II, glyceollin III, and phaseol that are biosynthesized from the intermediate daidzein, and $\beta_{\text {prenyl }}$ genistein that is biosynthesized from genistein (Fig. 1). We also measured the levels of an unknown metabolite that exhibited UV absorbance properties similar to isoflavonoids but did not represent any of the 57 (iso)flavonoid standards that we have in our library. 


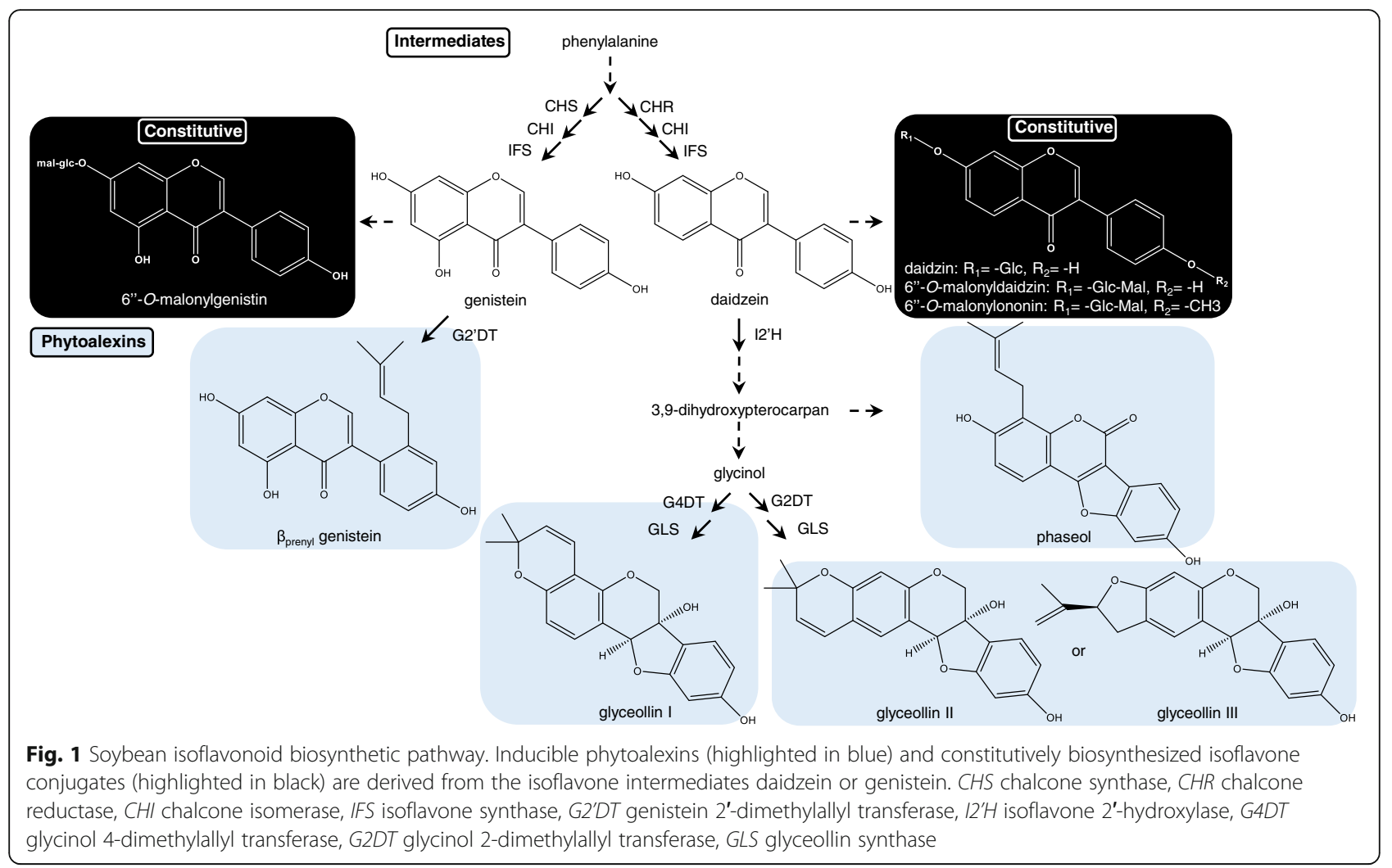

The MS medium high light condition was the only condition that elicited measurable amounts of all phytoalexins (Fig. 2a). The MS low light condition had greater amounts of glyceollins I and II but lacked phaseol and $\mathrm{B}_{\text {prenyl }}$-genistein, and thus may not be suitable for evaluating the specificity of the effects of abiotic stresses on the glyceollin pathway. Glyceollins were absent or in trace amounts in seedlings grown on soil, either under the high or low light conditions. Based on these results, we selected the MS medium high light as the control condition to evaluate the effects of abiotic stresses on glyceollin biosynthesis.

Seedlings were transferred to eight abiotic stress conditions and the amounts of total phytoalexins were enhanced significantly by $\mathrm{pH} 3.0$ medium, UV-C, and dehydration compared to the control (ANOVA, Tukey post hoc test, $P<0.01$ ) (Fig. $2 b$ ). $\mathrm{pH} 3.0$ medium stimulated the greatest increase, having 22.7-fold greater amounts of total phytoalexins compared to the control and significantly greater amounts compared to all other treatments. UPLC-PDA chromatograms revealed major increases in the levels of glyceollins for pH 3.0 medium, and major reductions in the amounts of 6-O-malonyldaidzin for dehydration and $\mathrm{pH} 3.0$ medium that were not observe for the UV-C treatment (Fig. 2c). pH 3.0 medium and dehydration predominantly caused increases in the amounts of glyceollin III and glyceollin II
(Fig. 2d). Overall, pH 3.0 medium had the greatest increase in glyceollin amounts, with glyceollin III becoming $25 \%$ of the total measured isoflavonoid content.

\section{Acidity stress enhances and dehydration suppresses glyceollin biosynthesis}

Pathogens generally elicit maximum glyceollin biosynthesis within $24-48 \mathrm{~h}$ of inoculation, then the levels rapidly decline $[4,35]$. To understand the dynamics of the regulation of glyceollin biosynthesis by $\mathrm{pH} 3.0$ medium and dehydration, we measured metabolite levels at regular intervals up to 9 dat.

Following the transfer of seedlings to the control condition, we observed a gradual accumulation of glyceollins and phaseol peaking at 6 dat (Fig. 3a). In contrast,

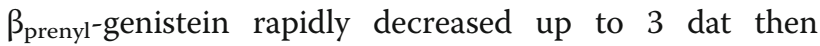
remained constant thereafter. Two elicitation patterns distinguished pH 3.0 medium from the control. Glyceollin III and phaseol exhibited sharp increases from 6 dat to 9 dat, whereas glyceollins I and II exhibited delayed and prolonged accumulation (Fig. 3a). Elicitation of these daidzein-derived phytoalexins was accompanied by decreases in daidzein and its glycosyl-conjugates, namely daidzin and 6-O-malonyldaidzin. Genistein and derived isoflavonoids were not increased by pH 3.0 medium. In sharp contrast, dehydration caused a sustained suppression of all daidzein-derived isoflavonoids over the $9 \mathrm{~d}$ 

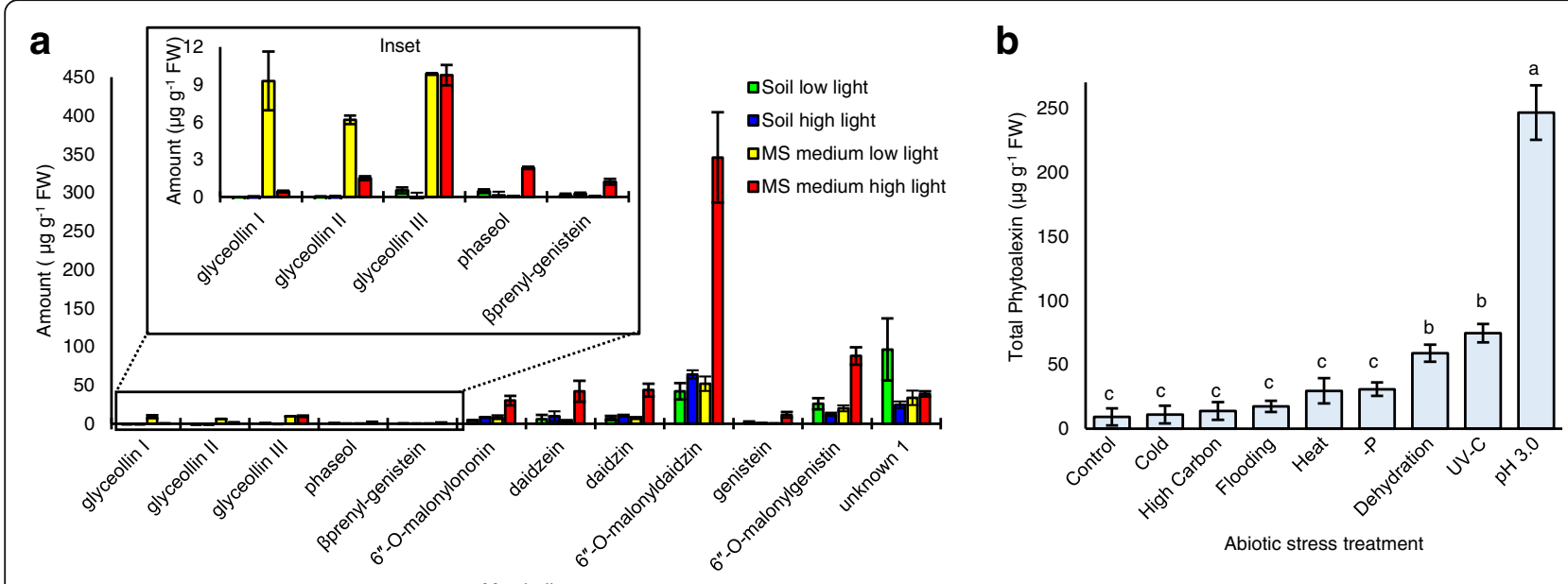

C
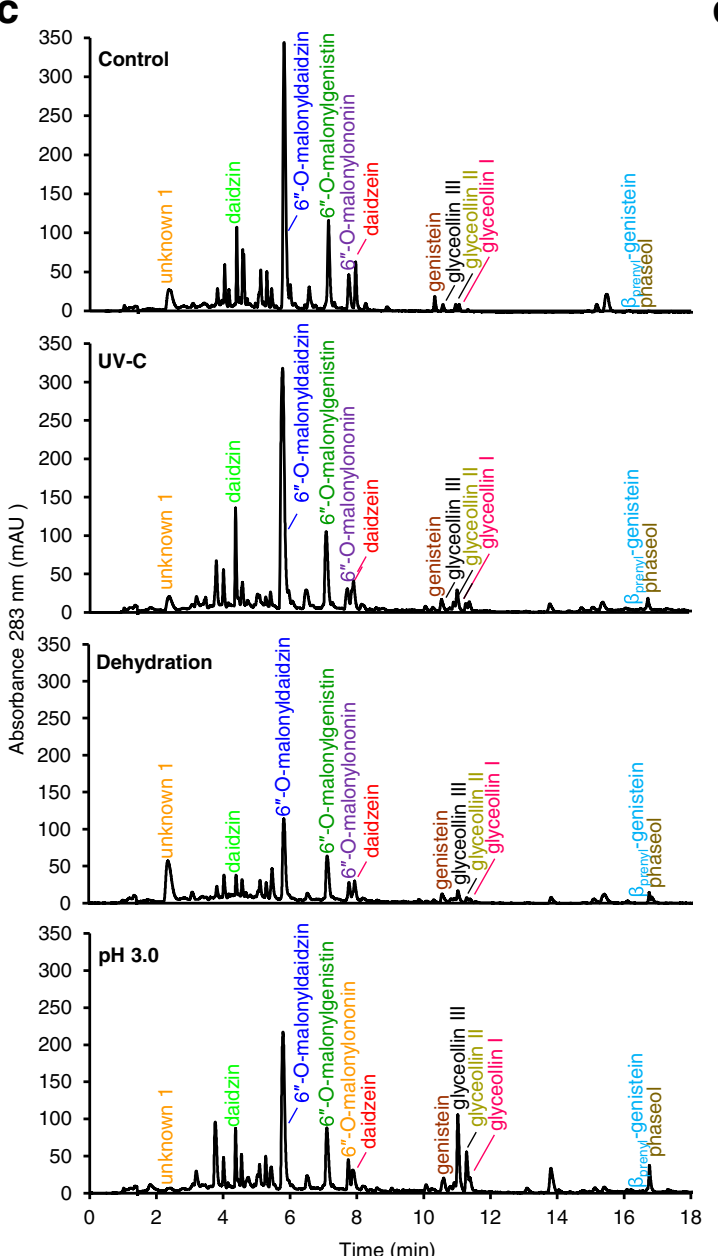

d
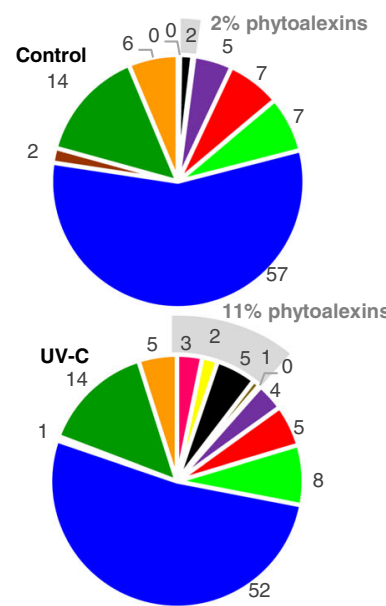

Dehydration

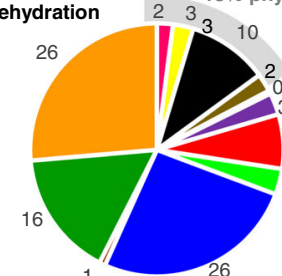

pH 3.0

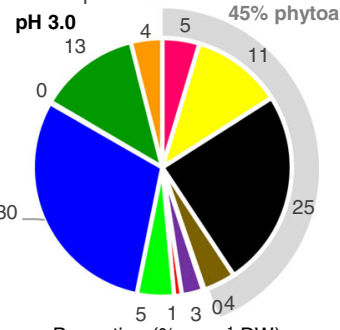

glyceollin I

glyceollin II

glyceollin III

phaseol

ßprenyl-genistein

6"-O-malonylononin

daidzein

daidzin

6"-O-malonyldaidzin

genistein

6"-O-malonylgenistin

unknown 1

Fig. 2 Phytoalexin and isoflavonoid content in response to abiotic stresses. a Effects of light and growth medium on phytoalexin elicitation in Harosoy 63 seedlings. Error bars represent standard error of mean. $\mathbf{b}$ Effects of different abiotic stress treatments phytoalexin elicitation. Total phytoalexins represent the sum of glyceollins I-II, phaseol, and Bprenyl-genistein. Different letters show significant differences by single factor ANOVA, Tukey post hoc test, $P<0.01$. Error bars represent standard error of mean. $\mathbf{c}$ UPLC-PDA chromatograms of ethanolic extracts at $283 \mathrm{~nm}$. $\mathbf{d}$ Proportions of the metabolites labeled in $C$ based on their tissue concentration ( $\mathrm{mg} \mathrm{g}^{-1} \mathrm{DW}$ ) 


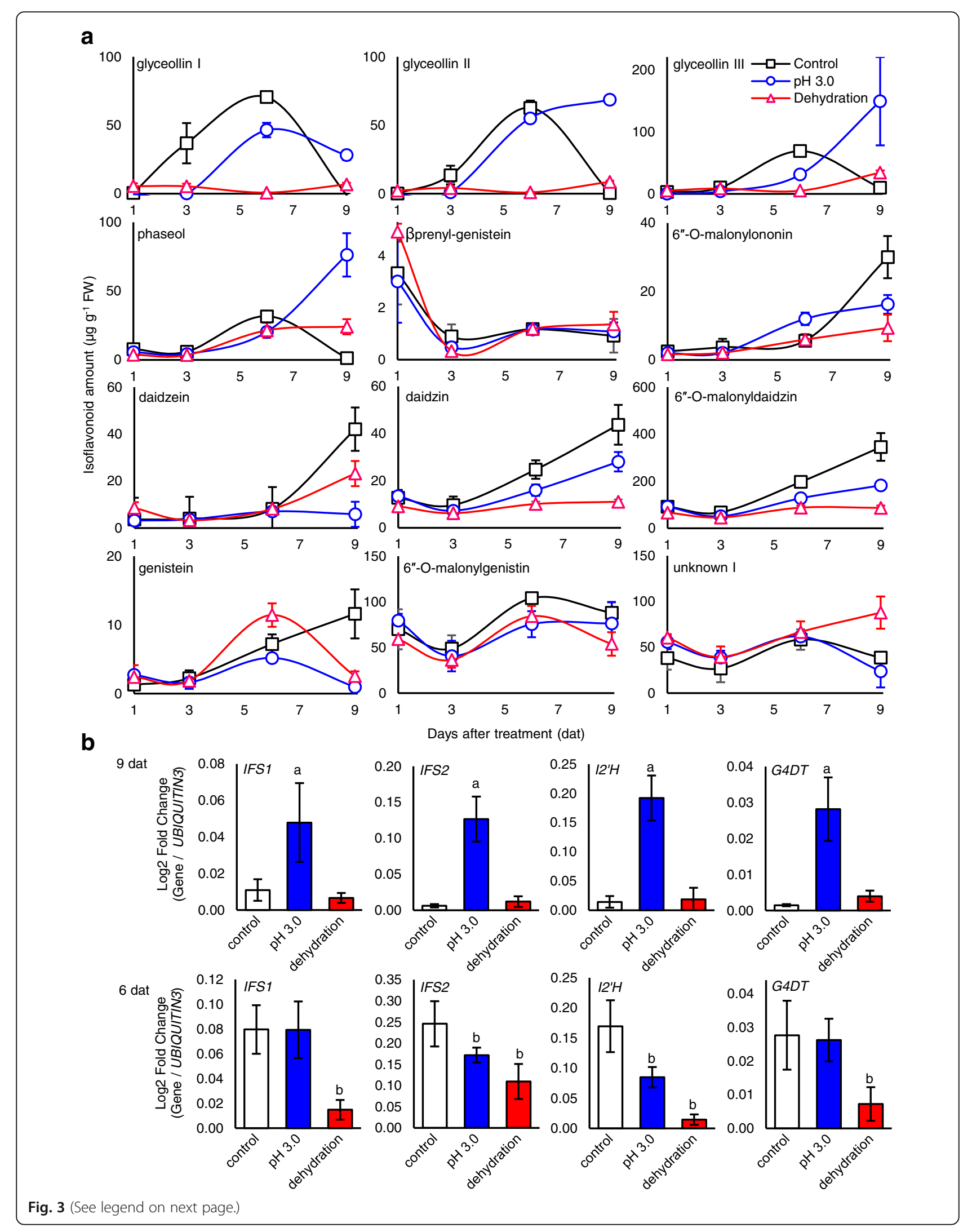


(See figure on previous page.)

Fig. 3 Time course of phytoalexin and isoflavonoid biosynthesis during acidity and dehydration stresses. a Isoflavonoid levels by UPLC-PDA over time after transfer to the control condition, pH 3.0 medium, or dehydration stress. Error bars represent standard error of mean. $\mathbf{b}$ Isoflavonoid biosynthesis gene expressions at 6 and 9 dat measured by qRT-PCR. ${ }^{a}$ Significantly greater and ${ }^{b}$ significantly less than control, paired students $t$-test $(P<0.01)$. Error bars represent standard error of mean

period with up to a 106.8-fold suppression of glyceollin I at 6 dat (Fig. 3a). This major suppressive effect was not observed for genistein-derived metabolites.

To determine whether $\mathrm{pH} 3.0$ medium and dehydration stresses regulated glyceollin biosynthesis gene transcripts, we measured the expression of key biosynthetic genes by quantitative reverse transcriptase-polymerase chain reaction (qRT-PCR). Specifically, we measured the expressions of isoflavone synthase 1 (IFS1) and IFS2, isogenes for the biosynthesis of isoflavones (Fig. 1). We also measured the expressions of isoflavone 2 '-hydroxylase $(I 2 ' H)$ and glycinol 4-dimethylallyltransferase (G4DT), genes for the biosynthesis of all daidzein-derived phytoalexins and glyceollin I, respectively [36, 37].

$\mathrm{pH} 3.0$ medium upregulated all gene transcripts at 9 dat. The levels ranged from 4.4- to 20.7-fold greater than the control for $I 2^{\prime} H$ and IFS2, respectively (Fig. 3b). By contrast, dehydration stress had reduced levels of all gene transcripts at 6 dat, ranging from 2.2- to 11.7-fold less than the control for IFS 2 and $I 2 ' H$, respectively.

\section{Acidity and dehydration stresses oppositely regulate all known glyceollin biosynthesis genes}

To investigate whether $\mathrm{pH} 3.0$ medium and dehydration oppositely regulated all known glyceollin biosynthesis genes, we conducted RNA-seq comparing genes upregulated by $\mathrm{pH} 3.0$ medium to those downregulated by dehydration.

pH 3.0 medium upregulated 3242 and dehydration downregulated 9129 genes more than 2-fold, respectively $(P<0.05)$ (Additional file 3: Table S3 and Additional file 4: Table S4). By comparing the two gene lists, we found that 1058 genes were in common (Fig. 4a \& Additional file 5: Table S5). All 27 known glyceollin biosynthesis genes spanning from phenylalanine ammonia lyase $(P A L)$ to the glycinol:dimethylallyl diphosphate (DMAPP) transferases G4DT and G2DT [37, 38] were upregulated by $\mathrm{pH} 3.0$ medium and downregulated by dehydration, respectively (Table 1). Since DMAPP is derived from either the cytosolic mevalonate pathway or the plastidic methylerythritol phosphate (MEP) pathway, we checked our lists for these genes. pH 3.0 and dehydration stresses oppositely regulated genes for all steps of the MEP pathway up to DMAPP formation, whereas no mevalonate genes were differentially regulated (Table 1 ).

Since our RNA-seq analyses found that pH 3.0 medium and dehydration regulated glyceollin biosynthesis at the level of transcription, we hypothesized that TF genes required for the activation of those biosynthesis genes would also be present in our geneset. Yet, all previously identified isoflavonoid TF genes were not found. Those absent included TF genes identified by QTL mapping of isoflavonoid amounts, namely GmMYBJ3 (Glyma.06 g193600) or GmMYB29 (Glyma20g35180) [39, 40]. Also absent were TFs that activated the biosynthesis of chalcone synthase-derived isoflavonoids during seed development, namely GmMYB176 (Glyma.05G032200) and GmCYP1 (Glyma.11G098700) [41, 42].

\section{Comparative transcriptomics identifies candidate transcription factors for the regulation of glyceollin biosynthesis}

To better understand the pathways that were oppositely regulated by acidity and dehydration stresses, we analyzed the ontologies of the 1058 oppositely regulated genes (Fig. 4a). Signal transduction was the most common category of ontology (31.4\% of genes, Fig. 4b). When the signal transduction category was broken down into ontologies, the greatest proportion (28.3\%) were annotated as systemic acquired resistance (SAR) (Fig. 4c). SAR is a component of the plant immune system whereby tissues distant from a pathogen infection site become primed (sensitized) to more rapidly activate resistance responses the second time the plant encounters the pathogen. Gene ontology (GO) enrichment analysis indicated that SAR genes were significantly enriched $\left(P<1.0^{-10}\right)$ and included those involved of salicylic acid (SA)-dependent and independent signaling pathways, in addition to jasmonic acid (JA) and ethylene signaling pathways (GO:0009627, GO:0009862, GO:0009864, GO:0009871, and GO:0010112). The SAR genes included homologs of AGD2-LIKE DEFENSE RESPONSE PROTEIN 1 (ALD1) and FLAVIN-DEPENDENT-MONOOXYGENASE1 (FMO1) that were indispensable for SAR in Arabidopsis (Table 2) [43-45]. ALD1 encodes an enzyme that synthesizes the non-protein amino acid pipecolic acid (Pip) from Lys upon pathogen attack [45]. FMO1 converts Pip to N-hydroxypipecolic acid (NHP) [46] and is needed for Pip to orchestrate priming of pathogen responses by SAdependent and independent pathways [47]. The SAR genes also included homologs of signaling and TF genes that had roles in regulating the elicitation of the indole alkaloid phytoalexin camalexin in Arabidopsis. PHYTOALEXIN DEFICIENT4 (PAD4) is a lipase-like gene required for SA-dependent elicitation of camalexin in response to microbial pathogens [48]. SIGMA FACTOR 


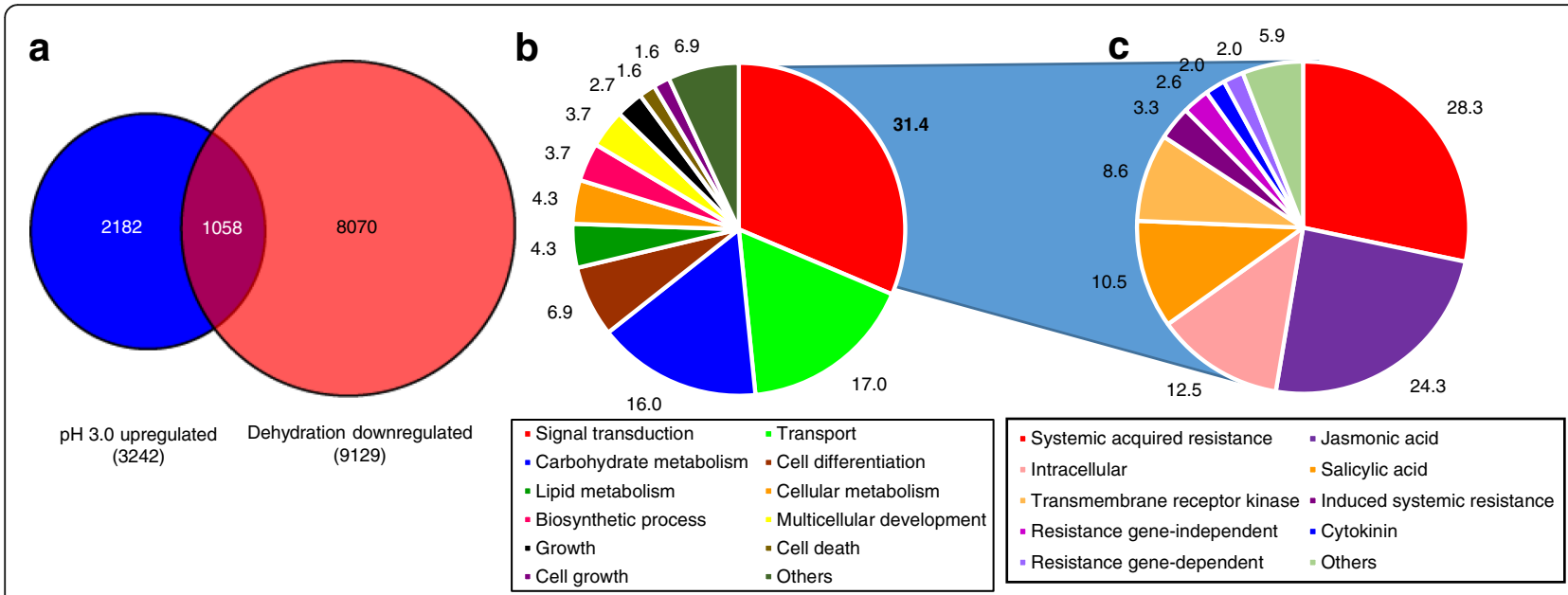

Fig. 4 Comparative transcriptomics of seedlings treated with acidity stress or dehydration. a Number of genes in Harosoy 63 seedlings that were upregulated and downregulated more than 2-fold by pH 3.0 medium and dehydration, respectively $(P<0.05)$ by RNA-seq. b Percent of genes upregulated by pH 3.0 medium and downregulated by dehydration stress assigned to a category of gene ontology. c Breakdown of the 'Signal transduction' category into gene ontologies. Ontology analysis was conducted using the SoyBase Gene Model Data Mining and Analysis tool

BINDING PROTEIN 1 (SIB1) encodes a TF that activates the expression of AtWRKY33, a direct regulator of camalexin biosynthesis genes [49]. However, homologs of AtWRKY33 (namely Glyma.02G232600 and Glyma.14G200200) were not found in our gene set nor were they significantly upregulated by pH 3.0 medium alone.

Among the putative soybean SAR genes were three homologs of the NAC [no apical meristem (NAM), Arabidopsis transcription activation factor [ATAF1/2] and cupshaped cotyledon (CUC2)] family gene ANAC042/AtJÜB1. ANAC042/AtJUB1 regulates camalexin biosynthesis in Arabidopsis in response to the ROS-inducing herbicide acifluorofen, Alternaria brassicicola, and bacterial flagellin (Flg22) [7].

\section{NAC42-type TFs are upregulated with glyceollins by abiotic and biotic elicitors}

We conducted qRT-PCR to gain insight into whether the NAC42-type TFs that were identified by our transcriptomics analysis may be involved in regulating glyceollin biosynthesis. qRT-PCR confirmed that the three GmNAC42s were upregulated by $\mathrm{pH} 3.0$ medium and downregulated by dehydration (Fig. 5a-b).

The predicted GmNAC42 proteins were $68.5-85.8 \%$ similar to each other and 54.3-56.7\% similar to ANAC042/ JUB1 with GmNAC42-1 being the most similar (Additional file 6: Table S6). The N-terminal halves of these proteins contained the conserved NAM domain (pfam02365) putatively involved in dimerization and binding DNA (Additional file 7: Fig. S1). The $\mathrm{N}$-terminal halves of the GmNAC42s were highly similar to ANAC042/JUB1 (76.2-83.3\%), whereas the C-terminal halves putatively involved in protein-protein interactions were highly divergent (30.5-34.9\% similarity)
(Additional file 6: Table S6). A phylogenetic analysis of the predicted GmNAC42 proteins with characterized NACs revealed that the GmNAC42s were most closely related to VvNAC42_5 (Fig. 5c). VvNAC42_5 is an SA-independent powdery mildew responsive gene from grapevine (Vitis vinifera) [50]. Also in this cluster were proteins that positively regulate drought stress responses, namely SIJUB1 and DINAC1 [51, 52].

To probe further whether GmNAC42s may be positive regulators of glyceollins, we assessed whether their gene expressions were upregulated by the wall glucan elicitor (WGE) from P. sojae.

Treatment of soybean hairy roots with WGE resulted in maximum accumulation of glyceollins at $24 \mathrm{~h}$ after treatment (Fig. 5d). qRT-PCR found that all three GmNAC42s were upregulated 9.6- to 14.4-fold at this time with the glyceollin biosynthesis gene G4DT (Fig. 5e). GmNAC42-1 was the most highly upregulated.

\section{GmNAC42-1 regulates glyceollin biosynthesis in response to Phytophthora sojae WGE}

We chose to investigate the function of GmNAC42-1 since it is the soybean homolog of $A N A C 042$, an indole alkaloid phytoalexin regulator from Arabidopsis, and since its gene expressions coincided with the elicitation of glyceollin biosynthesis. If GmNAC42-1 positively regulates glyceollin biosynthesis, silencing its gene expressions in elicited tissues should reduce the accumulation of glyceollin metabolites and biosynthesis gene transcripts. Conversely, overexpressing GmNAC42-1 should increase the accumulation of glyceollins and their biosynthesis gene transcripts. To test, we produced soybean hairy roots harboring an RNA interference (RNAi) construct that encoded a hairpin dsRNA identical to a 


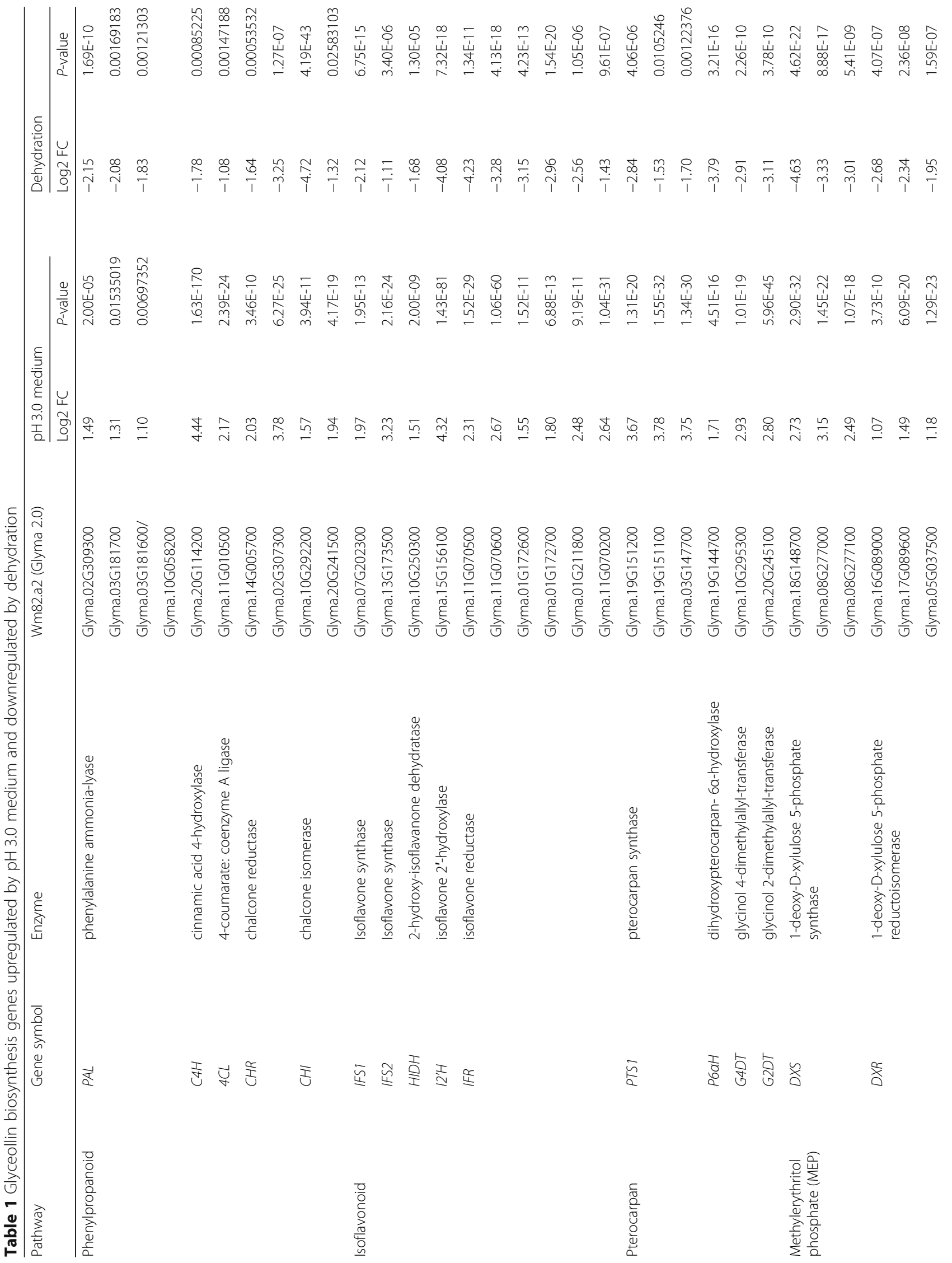




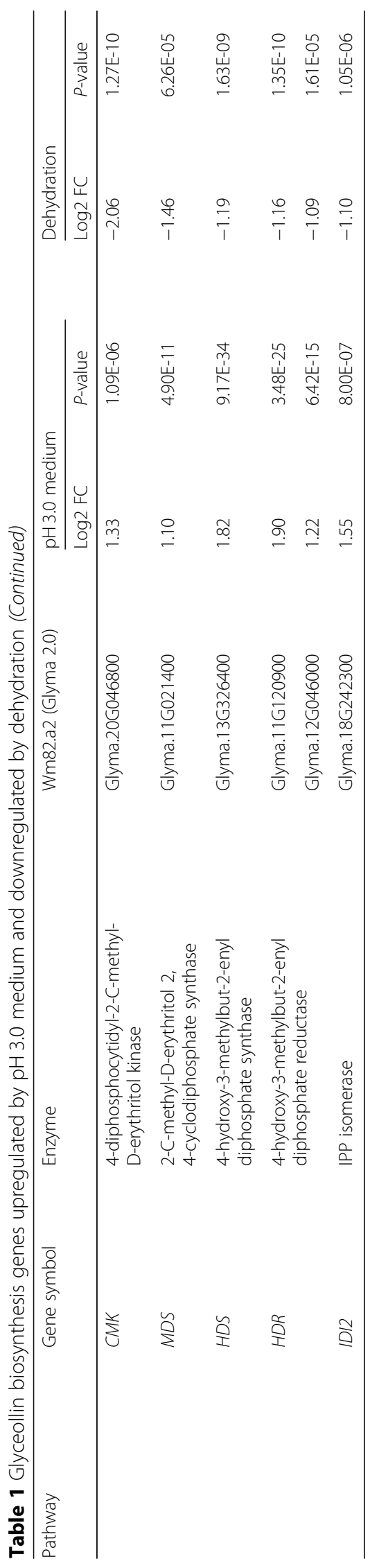




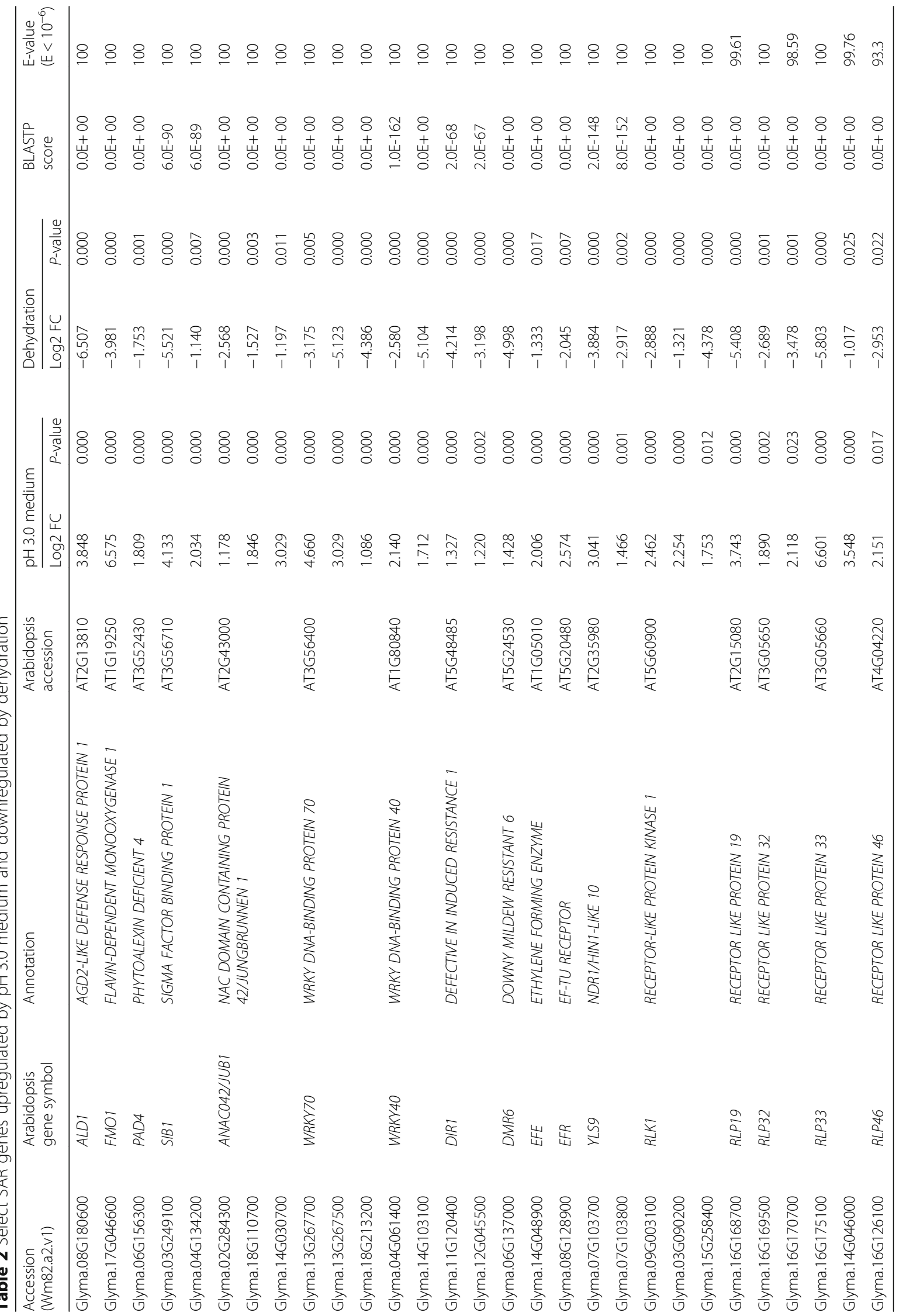




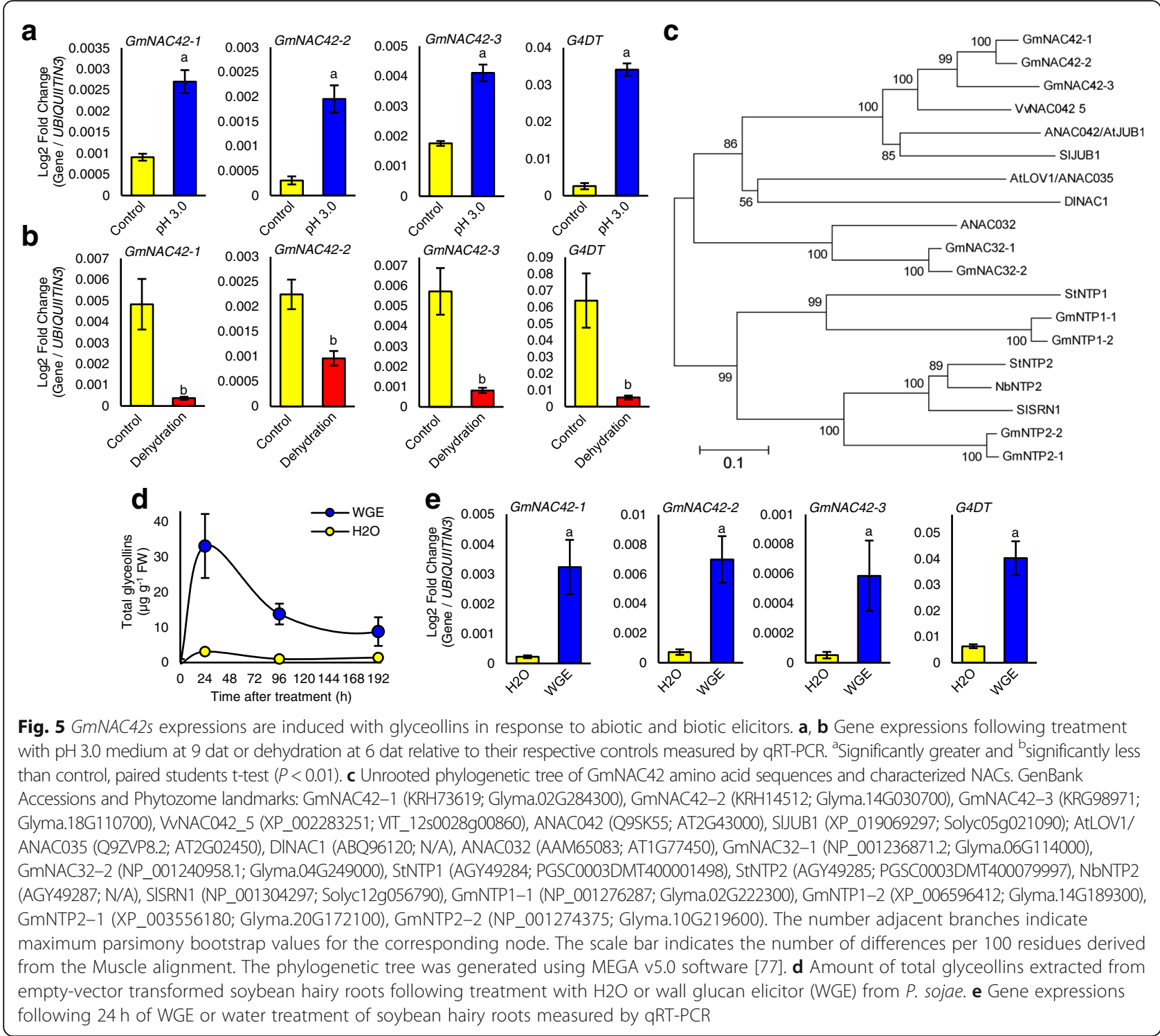

227 bp region of exon 2 of GmNAC42-1 and roots that overexpressed the GmNAC42-1 open reading frame (ORF) via the constitutive cauliflower mosaic virus promoter (p35S).

A 2.0-fold silencing of GmNAC42-1 decreased the accumulations of glyceollin biosynthesis gene transcripts IFS1, IFS2, and G4DT 1.8- to 2.4-fold (Fig. 6a). Off-target silencing of GmNAC42-2 was observed but not for GmNAC42-3. The overexpression of GmNAC42-1 upregulated IFS1, IFS2, and G4DT from 2.1- to 8.3-fold in roots treated with WGE or mock $\left(\mathrm{H}_{2} \mathrm{O}\right)$ (Fig. 6b-c).

RNAi silencing of WGE-elicited roots decreased the amounts of glyceollin I, II and III 4.0-, 2.8- and 3.2-fold, respectively (Fig. 6d). It also caused 2.0 -fold decreases in the amounts of 6-O-malonyldaidzin and daidzin (Fig. 6d), consistent with decreased expressions of IFS2 (Fig. 6a). Overexpressing GmNAC42-1 in WGE-elicited roots resulted in 10.8-, 4.9-, and 3.0-fold increases in the amounts of glyceollin I, genistein, and glyceollin II, respectively (Fig. 6e). It also caused a 1.6-to 2.7 -fold reduction in the amounts of daidzin and 6-O-malonyldaidzin, consistent with upregulating G4DT (Fig. 6b). In the absence of WGE treatment, the overexpression of GmNAC42-1 alone was not sufficient to stimulate glyceollin accumulation, reflecting its inability to upregulate all glyceollin-specific biosynthesis genes when overexpressed. However, it did result in a 2.4-fold reduction in the amounts of 6-O-malonyldaidzin [21].

\section{GmNAC42-1 localizes to the nucleus and directly binds the promoters of glyceollin biosynthesis genes}

To determine whether the subcellular localization of the GmNAC42-1 protein was consistent with its putative role as a TF, we cloned its ORF downstream of an 
a

WGE $\square$ RNAi-vector $\square$ RNAi-GmNAC42-1

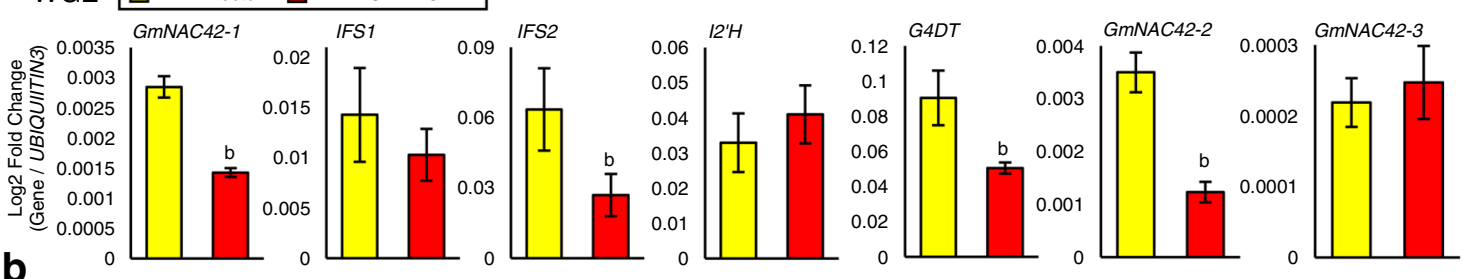

b

WGE $\square$ p35S::vector $\square$ p35s: GmNAC42-1

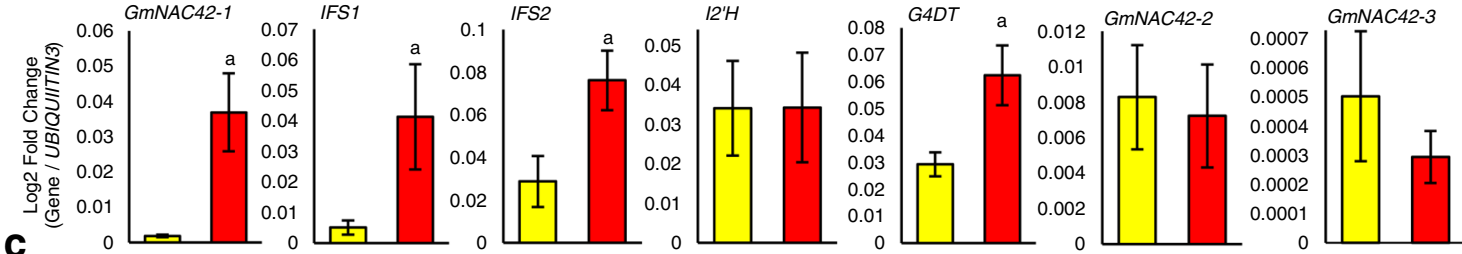

$\mathrm{H} 2 \mathrm{O} \square$ p35s::vector $\square$ p35s::GmNAC42-1

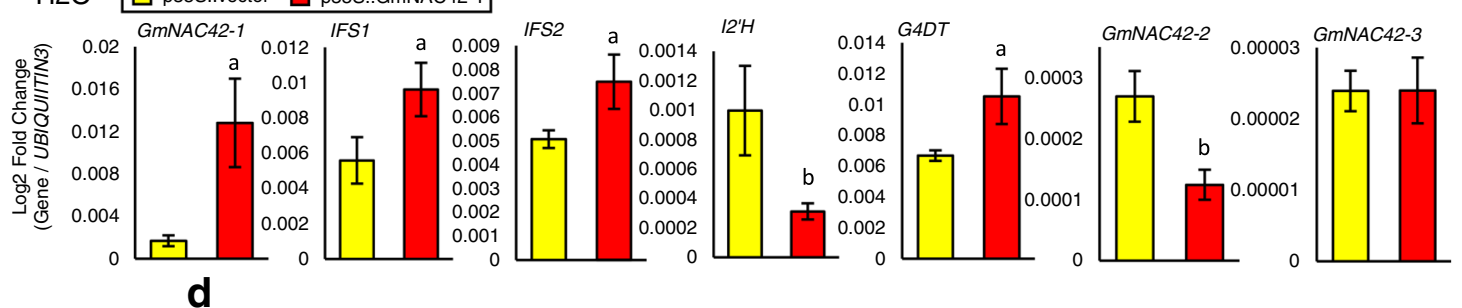

d

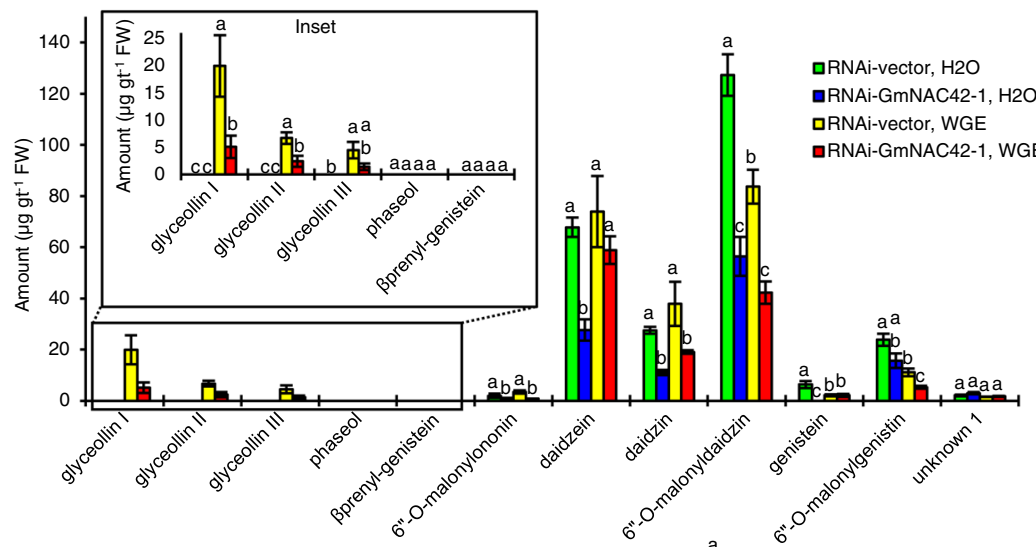

e

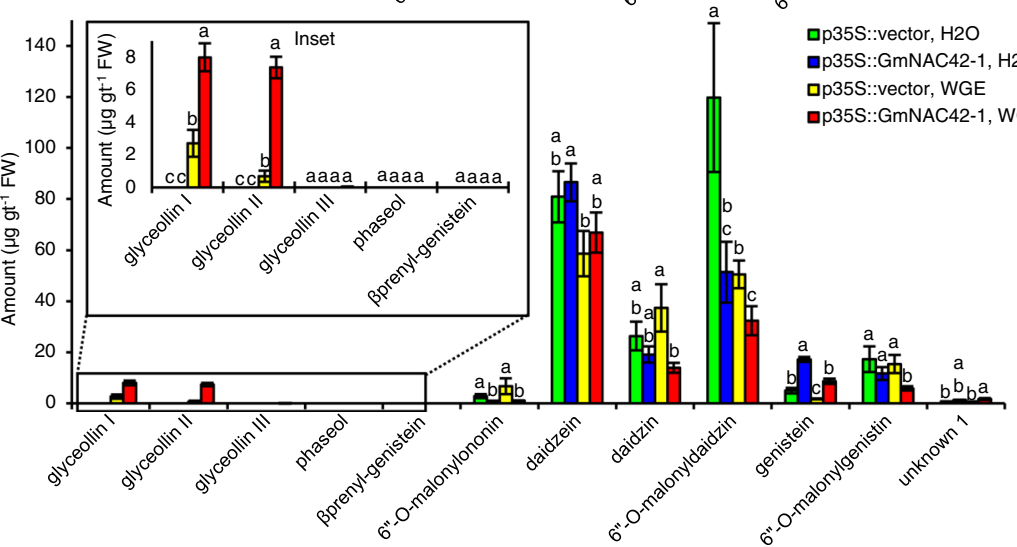

Fig. 6 (See legend on next page.) 
(See figure on previous page.)

Fig. 6 Overexpression and silencing of GmNAC42-1 in soybean hairy roots. a Gene expressions in WGE-treated Williams 82 hairy roots undergoing RNAi silencing of GmNAC42-1. b Gene expressions in WGE-treated hairy roots overexpressing GmNAC42-1. c Gene expressions in mock-treated hairy roots overexpressing GmNAC42-1. Measurements were $24 \mathrm{~h}$ after treatment by qRT-PCR. ${ }^{\mathrm{a}}$ Significantly greater and ${ }^{\mathrm{b}}$ significantly less than control, paired students $t$-test $(P<0.01)$. d Amounts of phytoalexins and constitutive isoflavonoids in soybean hairy roots undergoing RNAi silencing of GmNAC42-1 24 h after treatment with WGE or H2O. e Metabolite amounts from hairy roots overexpressing GmNAC42-1. Different letters show significant differences by single factor ANOVA, Tukey post hoc test, $P<0.01$

N-terminal GFP tag and expressed the translational fusion in soybean hairy roots using the constitutively active CaMV-35S promoter (p35S) [53]. nGFP-GmNAC42-1 localized to the nucleus as shown by co-localization with propidium iodide fluorescence (red arrowheads, Fig. $7 \mathrm{a}-\mathrm{c}$ ). By contrast, GFP expressed by the empty vector localized to the cytosol and other extra-nuclear compartments (Fig. 7d-f).

To test whether the GmNAC42-1 protein could directly bind the promoters of glyceollin biosynthesis genes, the ORF was also cloned downstream of the GAL4 activation domain and expressed in yeast harboring several $500 \mathrm{bp}$ segments of IFS2 or G4DT promoters (Fig. $7 \mathrm{~g}$ ). GmNAC42-1 weakly activated the G4DT promoter segment closest the transcription start site (G4DTpro1) that had one predicted NAC binding element (T/ATTGACT/ $C)$, failed to activate the segment that lacked the element (G4DTpro1), and strongly activated both IFS2 promoter segments that each had several elements (Fig. 7h).

\section{Discussion}

\section{GmNAC42-1 is required for full elicitation of glyceollin biosynthesis}

In this study, we found that transcripts of the NAC-family TF gene GmNAC42-1 were upregulated with glyceollin biosynthesis genes and metabolites when soybean tissues were elicited by acidity stress or the biotic elicitor WGE from $P$. sojae. They were also downregulated with glyceollin biosynthesis genes and metabolites by dehydration stress. The overexpression and silencing of GmNAC42-1 in WGE-treated hairy roots enhanced and suppressed, respectively, the expressions of the isoflavone biosynthetic genes IFS1 and IFS2, the glyceollin-specific gene G4DT, and the accumulation of glyceollin metabolites. Since G4DT is specifically involved in glyceollin biosynthesis, the results suggest that $G m N A C 42-1$ is a regulator of glyceollin elicitation and not the biosynthesis of constitutively accumulating isoflavone conjugates. However, overexpressing or silencing $G m N A C 42-1$ did not affect the expression levels of $I 2 ' H$, one of the key genes required for glyceollin biosynthesis [54]. Further, overexpression of GmNAC42-1 in the absence of WGE did not result in the accumulation of glyceollins. Thus, our results showed that GmNAC42-1 is required for the full elicitation of glyceollin biosynthesis in response to $P$. sojae WGE, but is not sufficient to upregulate all glyceollin biosynthesis genes.
The nGFP-GmNAC42-1 fusion protein localized to the nucleus in the absence of an elicitor treatment and thus did not rely on elicitor treatment for nuclear localization as observed for the phytoalexin TF AtWRKY33 or the NAC-family TFs StNTP1 and StNTP2 [55, 56]. Since GmNAC42-1 is essential for full elicitation of glyceollins, we suggest that GmNAC42-1 acts in concert with at least one other TF to coordinately activate all glyceollin biosynthetic genes. Further, by upregulating some but not all glyceollin genes, GmNAC42-1 could also function in SAR to prime soybean tissues distal to an inoculation site for subsequent rapid/high-level elicitation [23, 57, 58]. A subsequent direct inoculation of the primed tissues would activate the expressions or activity of one or more additional TFs that upregulates $I 2 ' H$ and other glyceollin biosynthesis genes that are not regulated by $G m N A C 42-1$ alone. In that case, overexpressing GmNAC42-1 could serve as an alternative to spraying the lactofen-containing herbicide Cobra that primes glyceollin biosynthesis to increase resistance against pathogens such as white mold, the causal agent of sclerotinia stem rot, without adversely effecting yield [59, 60]. Future experiments should test whether overexpressing GmNAC42-1 in soybean plants primes glyceollin biosynthesis without adverse effects on yield as well. Since the rapidity of glyceollin elicitation is a major factor that distinguishes resistant to $\underline{P}$. sojae (Rps) soybean genotypes from nearly-isogenic susceptible genotypes [61-64], experiments should also test whether overexpressing GmNAC42-1 enhances the rapidity of glyceollin elicitation in response to compatible $\underline{P}$. sojae (Rps) genotypes.

\section{GmNAC42-1 and a conserved phytoalexin elicitation \\ pathway}

The regulation of phytoalexins by pathogens and specific abiotic stresses suggests that elicitation is highly complex and may require multiple signaling pathways. This study in soybean identified acidity stress ( $\mathrm{pH} 3.0$ medium) and dehydration as novel regulators of phytoalexin biosynthesis. Transcriptome analysis found that the genes upregulated by acidity stress and downregulated by dehydration were reminiscent of pathogen responses, with SAR genes being highly overrepresented. The SAR genes included homologs of Arabidopsis ALD1 and FMO1 that synthesize the systemic signaling molecules Pip and its derivative $\mathrm{N}$-hydroxypipecolic acid (NHP) to orchestrate priming of 


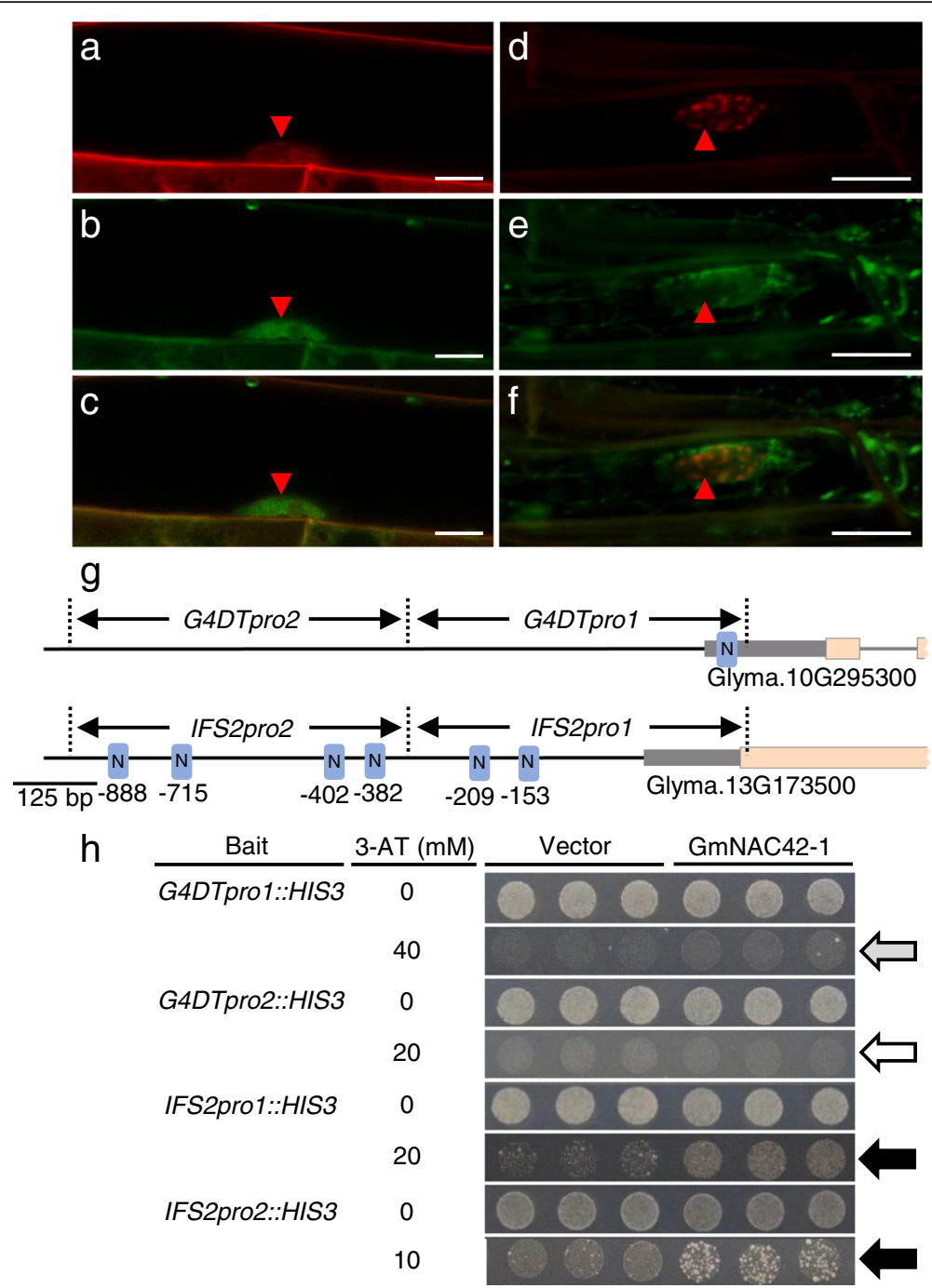

Fig. 7 Nuclear localization and DNA binding activities of GmNAC42-1. (a-f) Confocal fluorescence microscopy images of GFP-GmNAC42-1 fusion protein in transgenic soybean hairy roots. a-c Root cell expressing GFP-GmNAC42-1 fusion protein. $\mathbf{d}$-f Root cell expressing GFP. a Propidium iodide $\left(10 \mathrm{\mu g} \mathrm{mL}^{-1}\right)$ staining the plasma membrane and nucleus. b GFP-GmNAC42-1 fluorescence at plasma membrane and nucleus. c Overlay of GmNAC42-1 and propidium iodide fluorescence from panels $\mathbf{a}$ and $\mathbf{b}$. $\mathbf{d}$ Propidium iodide staining. e GFP signal in cytosol and other extranuclear compartments. f Overlay of GFP and propidium iodide fluorescence from D and E. Bars $=10 \mu \mathrm{m}$. g Schematic diagram demonstrating G4DT and IFS2 promoter fragments used for yeast one-hybrid assays and predicted NAC binding elements (blue boxes). $\mathbf{h}$ Yeast one-hybrid assays of YM4271 yeast transformed with GmNAC42-1 on SD/-His/-Leu medium containing various concentrations of 3-AT. Arrows: gray indicates weak binding, white no binding, and black strong binding

pathogen responses [46, 47], and the lipase-like and TF Arabidopsis genes PAD4 and ANACO42 that regulate the biosynthesis of camalexin in Arabidopsis [7, 48]. Here, we found that GmNAC42-1 is the soybean homolog of ANAC042 and is required for full elicitation of glyceollins. The results suggest a conserved phytoalexin elicitation pathway for phenylpropanoid-derived glyceollins in soybean and indole alkaloid-derived camalexin in Arabidopsis that requires NAC42 TFs. Further, our investigation of Lager's transcriptome dataset [65] demonstrated that $A N A C 042$ and its target camalexin biosynthesis genes (namely CYP71A12, CYP71A13 and CYP71B15/PAD3)
[7] were upregulated by long-term acidity stress, suggesting that NAC42-dependent induction of phytoalexins may be a conserved response to acidity stress.

More insight into the NAC42 pathway could be drawn from the fact that glyceollin biosynthesis was elicited by the treatment of soybean cotyledons with hydroxyl radical (a ROS) [24] and camalexin elicitation by the ROS-inducing herbicide acifluorofen required ANAC042 [7]. The ROS-inducing herbicide lactofen systemically primes glyceollin biosynthesis [59]. ROS accumulation is stimulated by various phytoalexin elicitors such as pathogens, heavy metals, and UV irradiation [66-68]. 
Further, the acidification of growth media from $\mathrm{pH} 5.0$ to 4.5 stimulated ROS production in seedlings of barley and Scots pine $[69,70]$ and in MS medium containing Plantago shoots [71]. Also, genes that positively regulate ROS (GO:2000377 and GO:2000379) were overrepresented in the soybean and Arabidopsis transcriptome responses to long-term acidity stress. Thus, the NAC42 pathway may be a conserved ROS signaling pathway responsible for phytoalexin elicitation in response to various abiotic and biotic elicitors. It is tempting to speculate that major TFs that regulate acidity and dehydration responses may regulate GmNAC42-1 since the stresses oppositely regulate $G m N A C 42-1$ transcripts. $S T O P 1$ is a zinc finger TF that is a major regulator of protective responses to acidity stress [72, 73]. STOP1 also stimulates ROS production [74]. Yet, STOP1 homologs were not found in the soybean transcriptome response to long-term acidity stress (9 dat), and ANACO42 was not downregulated in an Arabidopsis stop1 mutant at 1 dat [72]. This could infer that NAC42 induction of phytoalexins is downstream of ROS signaling and not directly regulated by $S T O P 1$. ABA is a major regulator of dehydration responses in part through the activity of ABA-responsive element (ABRE)-binding TFs [75]. Our transcriptome dataset shows that dehydration is a powerful negative regulator of glyceollin biosynthesis and GmNAC42-1, raising the possibility that both are negatively regulated by $\mathrm{ABA}$. We found that ABREs were present in the promoter regions ( 1000 bp upstream of the transcription start site) of several glyceollin biosynthesis genes, but no ABREs were observed in the GmNAC42-1 promoter (data not shown). Thus, dehydration may regulate glyceollin biosynthesis at multiple levels.

\section{Co-option of phytoalexin biosynthesis by NAC42}

Phytoalexin TF genes of the NAC, MYB, bHLH, and WRKY families have been identified from Arabidopsis, rice, cotton, maize and grapevine [5-10]. Yet none of these TF genes were homologous among plant species. The phytoalexins elicited in these species were biosynthetically diverse and included indole alkaloids, momilactones and phytocassanes, terpenoid aldehydes, deoxyanthocyanidins, and stilbenoids, respectively. Thus, it has remained a question whether any phytoalexin TFs are conserved in plants or whether they are as diverse as the biosynthetic pathways that they regulate. Here, we found that GmNAC42-1 is required for the full activation of glyceollin biosynthesis in soybean. Its homolog ANACO42 is needed for the full elicitation of camalexin biosynthesis in Arabidopsis [7]. Glyceollins are isoflavonoid derivatives derived from phenylalanine, whereas camalexin is an indole alkaloid biosynthesized from tryptophan. It is possible that NAC42 TFs regulate genes in the shikimate pathway that produces phenylalanine and tryptophan. Yet, our overexpression and silencing experiments demonstrated that GmNAC42-1 regulated isoflavonoid- and glyceollin-specific biosynthetic genes through the direct binding of their promoters. While our promoter sequence analyses identified the putative NAC-binding element T/ATTGACT/C within $1 \mathrm{~kb}$ of the translation start sites of the camalexin-specific biosynthetic genes CYP71A12 and CYP71A13 that were regulated at the mRNA level by $A N A C 042$ [7], the DREB2A element that was suggested to be the target of ANAC042/JUB1 [76] was not found in those regions nor within glyceollin biosynthetic gene promoters. If NAC42 TFs indeed bind the element T/ATTGACT/C element in glyceollin- and camalexin-specific biosynthetic genes, this would suggest that phytoalexin biosynthesis pathways were co-opted into stress-inducible regulation by NAC42 TFs. Our future work will focus on characterizing the recognition elements and DNA binding domains of GmNAC42-1 and ANAC042 that are required to activate phytoalexin biosynthesis.

\section{Conclusions}

GmNAC42-1 is essential for the full elicitation of glyceollins in soybean. It's overexpression in elicited soybean hairy roots enhanced the biosynthesis of glyceollins more than 10-fold. Thus, bioengineering the expressions of GmNAC42-1 may be a promising approach for bioproducing glyceollins for medicinal use or for enhancing soybean resistance to the economically destructive pathogen P. sojae. GmNAC42-1 is the first identified conserved regulator of phytoalexin biosynthesis and is a homolog of the indole alkaloid phytoalexin regulator ANAC042 from Arabidopsis. Possible implications are that NAC42-type TF genes could be used in a wide variety of crop plants to enhance the bioproduction of medicinal metabolites or for improving crop resistance to pathogens.

\section{Additional files}

Additional file 1: Table S1. Sequences of primers used in the experiments. (XLSX $11 \mathrm{~kb}$ )

Additional file 2: Table S2. Sequences of promoters used in yeast one-hybrid experiments. (XLSX $12 \mathrm{~kb}$ )

Additional file 3: Table S3. Genes upregulated by pH 3.0 medium compared to control at 9 dat in Harosoy 63 soybean seedlings. (XLSX $193 \mathrm{~kb}$ )

Additional file 4: Table S4. Genes downregulated by dehydration in Harosoy 63 soybean seedlings compared to the control at 6 days after treatment. (XLSX $503 \mathrm{~kb})$

Additional file 5: Table S5. Genes upregulated by pH 3.0 medium compared to control at 9 dat and downregulated by dehydration compared to control at 6 dat in Harosoy 63 soybean seedlings. (XLSX $105 \mathrm{~kb}$ )

Additional file 6: Table S6. Amino acid similarities of NAC42 proteins from soybean, Arabidopsis and grapevine. Full-length proteins ( $\mathrm{N}$-terminal and C-terminal halves). (XLSX $11 \mathrm{~kb}$ )

Additional file 7: Figure S1. Amino acid alignment of NAC42 proteins from soybean, Arabidopsis and grapevine. (DOCX $14 \mathrm{~kb}$ ) 


\section{Abbreviations}

ABRC: Arabidopsis Biological Resource Center; ABRE: ABA-responsive element; AgNO3: silver nitrate; ALD1: AGD2-LIKE DEFENSE RESPONSE PROTEIN 1; aos: allene oxide cyclase; CAD1: (+)- $\delta$-cadinene synthase; CUC2: Cup-shaped cotyledon; CuCl2: Copper chloride; DMAPP: Dimethylallyl diphosphate; DW: Dry weight; FDR: False discovery rate; FMO1: FLAVIN-DEPENDENTMONOOXYGENASE1; FW: Fresh weight; G4DT: Glycinol:4-dimethylallyl diphosphate transferase; G4DTpro1: G4DT gene promoter segment1; GC: Germination and co-cultivation; GRN: Gene regulatory network; HRG: Hairy root growth; MeJA: Methyl jasmonate; MEP: Methylerythritol phosphate; MS: Murashige and Skoog; NAM: No apical meristem; nGFP: Nterminal GFP tag; NHP: N-hydroxypipecolic acid; PAD4: PHYTOALEXIN DEFICIENT4; PAL: Phenylalanine ammonia lyase; PaNie: Pythium aphanidermatum; Pip: Pipecolic acid; qRT-PCR: quantitative reverse transcriptase-polymerase chain reaction; RIN: RNA Integrity Number: RNAi: RNA interference; RNA-seq: RNA sequencing; ROS: Reactive oxygen species; Rps: Resistant to P. sojae; SAR: Systemic acquired resistance; SDHis: Synthetic dropout medium lacking histidine; SIB1: SIGMA FACTOR BINDING PROTEIN 1; STS: STILBENE SYNTHASE; TF: Transcription factor; WGE: Wall glucan elicitor; Y1H: Yeast one-hybrid; 3-AT: 3-amino-1,2,4-triazole; ATAF1/2: Arabidopsis transcription activation factor; NAC: NAM/ATAF1/2/ CUC2; osjar1-2: Oryza sativa jasmonic acid-amido synthetase

\section{Acknowledgements}

We would like to acknowledge the WVU Genomics Core Facility, Morgantown W for support provided to help make this publication possible. We thank Gustavo MacIntosh and Jessica Hohenstein (lowa State University) for Agrobacterium rhizogenes strain K599, Wayne Parrott and Tim Chappell (University of Georgia) for the soybean hairy root transformation protocol, Brett Tyler (Oregon State University) for race 1 P. sojae, Erich Grotewold (University of Michigan) for the yeast YM4271, Tsuyoshi Nakagawa (Shimane University) for the pGWB2 vector, the ABRC (Columbus, OH) for pDEST-GADT7, and Hiroyuki Tsuji (Yokohama City University) and the late Ko Shimamoto for PANDA35HK. We acknowledge use of the WVU Shared Research Facilities UPLC-PDA-MS Imaging experiments were performed at the West Virginia University Microscope Imaging Facility, which has been supported by the WVU Cancer Institute and NIH grants P20RR016440 and P3ORR032138, P30GM103488 and U54GM104942 for the Nikon A1R/N SIM-E.

\section{Funding}

This work was supported by WVU start-up funds to NK and was based upon work that is supported by the USDA National Institute of Food and Agriculture, Hatch, accession number 1010200, and the West Virginia Agricultural and Forestry Experiment Station project WVA00687.

\section{Availability of data and materials}

All RNA-seq data are available in the Gene Expression Omnibus (https:// www.ncbi.nlm.nih.gov/geo/) under the series accession GSE112584.

\section{Authors' contributions}

M.A.J. conducted UPLC-PDA-MS ${ }^{n}$ and statistics, B.H., K.C., and M.A.J. soybean hairy root transformations, M.L. qRT-PCR, B.H. Y1H; A.G.A. microscopy, R.J.P. RNA-seq library preparation and A.M.I. processed data. N.K. cloning, yeast transformations, supervised research, analyzed data, and wrote the manuscript. All authors read and approved the final manuscript.

\section{Ethics approval and consent to participate}

Not applicable.

\section{Consent for publication}

No applicable.

\section{Competing interests}

The authors declare that they have no competing interests.

\section{Publisher's Note}

Springer Nature remains neutral with regard to jurisdictional claims in published maps and institutional affiliations.

\section{Author details}

'Division of Plant and Soil Sciences, West Virginia University, Morgantown, West Virginia 26506, USA. ²Department of Biology, West Virginia University, Morgantown, West Virginia 26506, USA. ${ }^{3}$ Department of Biochemistry, West Virginia University, Morgantown, West Virginia 26506, USA. ${ }^{4}$ Department of Biostatistics, West Virginia University, Morgantown, West Virginia 26506, USA. ${ }^{5}$ Microscope Imaging Facility, West Virginia University, Morgantown, West Virginia 26506, USA.

Received: 24 September 2018 Accepted: 11 February 2019

Published online: 20 February 2019

\section{References}

1. Müller KO, Meyer G, Klinkowski M. Physiologisch-genetische Untersuchungen über die Resistenz der Kartoffel gegenüber Phytophthora infestans. Naturwissenschaften. 1939;27(46):765-8.

2. Graham TL, Graham MY, Subramanian S, Yu O. RNAi silencing of genes for elicitation or biosynthesis of 5-deoxyisoflavonoids suppresses race-specific resistance and hypersensitive cell death in Phytophthora sojae infected tissues. Plant Physiol. 2007;144(2):728-40.

3. Lygin AV, Zernova OV, Hill CB, Kholina NA, Widholm JM, Hartman GL, Lozovaya W. Glyceollin is an important component of soybean plant defense against Phytophthora sojae and Macrophomina phaseolina. Phytopathology. 2013;103(10):984-94.

4. Yoshikawa M, Yamauchi K, Masago H. Glyceollin: its role in restricting fungal growth in resistant soybean hypocotyls infected with Phytophthora megasperma var. sojae. Physiol Plant Pathol. 1978;12(1):73-82.

5. Ibraheem F, Gaffoor I, Tan Q, Shyu C-R, Chopra S. A sorghum MYB transcription factor induces 3-deoxyanthocyanidins and enhances resistance against leaf blights in maize. Molecules. 2015;20(2):2388-404.

6. Ogawa S, Miyamoto K, Nemoto K, Sawasaki T, Yamane H, Nojiri H, Okada K. OsMYC2, an essential factor for JA-inductive sakuranetin production in rice, interacts with MYC2-like proteins that enhance its transactivation ability. Sci Rep. 2017;7:40175

7. Saga H, Ogawa T, Kai K, Suzuki H, Ogata Y, Sakurai N, Shibata D, Ohta D. Identification and characterization of ANACO42, a transcription factor family gene involved in the regulation of camalexin biosynthesis in Arabidopsis. Mol Plant Microbe In. 2012;25(5):684-96.

8. Xu Y-H, Wang J-W, Wang S, Wang J-Y, Chen X-Y. Characterization of GaWRKY1, a cotton transcription factor that regulates the sesquiterpene synthase gene (+)- $\delta$-cadinene synthase-a. Plant Physiol. 2004;135(1):507-15.

9. Yamamura C, Mizutani E, Okada K, Nakagawa H, Fukushima S, Tanaka A, Maeda S, Kamakura T, Yamane H, Takatsuji H, et al. Diterpenoid Phytoalexin factor, a bHLH transcription factor, plays a central role in the biosynthesis of Diterpenoid Phytoalexins in Rice. Plant J. 2015;84(6):1100-13.

10. Zheng Z, Qamar SA, Chen Z, Mengiste T. Arabidopsis WRKY33 transcription factor is required for resistance to necrotrophic fungal pathogens. Plant J. 2006;48(4):592-605.

11. Ahuja I, Kissen R, Bones AM. Phytoalexins in defense against pathogens. Trends Plant Sci. 2012;17(2):73-90.

12. Großkinsky DK, van der Graaff E, Roitsch T. Phytoalexin transgenics in crop protection — fairy tale with a happy end? Plant Sci. 2012;195:54-70.

13. Jeandet P: Phytoalexins: current progress and future prospects. In: Multidisciplinary Digital Publishing Institute; 2015.

14. Marti G, Schnee S, Andrey Y, Simoes-Pires C, Carrupt P-A, Wolfender J-L, Gindro K. Study of leaf metabolome modifications induced by UV-C radiations in representative Vitis, Cissus and Cannabis species by LC-MS based metabolomics and antioxidant assays. Molecules. 2014;19(9):14004-21.

15. Park HL, Lee S-W, Jung $\mathrm{K}-\mathrm{H}$, Hahn T-R, Cho M-H. Transcriptomic analysis of UVtreated rice leaves reveals UV-induced phytoalexin biosynthetic pathways and their regulatory networks in rice. Phytochemistry. 2013;96:57-71.

16. Kato H, Kodama O, Akatsuka T. Oryzalexin E, a diterpene phytoalexin from UV-irradiated rice leaves. Phytochemistry. 1993;33(1):79-81.

17. Mert-Turk F, Bennett MH, Mansfield JW, Holub EB. Quantification of camalexin in several accessions ofArabidopsis thaliana following inductions withPeronospora parasitica and UV-B irradiation. Phytoparasitica. 2003;31(1):81-9.

18. Reilly JJ, Klarman WL. Thymine dimer and glyceollin accumulation in UVirradiated soybean suspension cultures. Environ Exp Bot. 1980;20(2):131-4.

19. Miyamoto K, Enda I, Okada T, Sato Y, Watanabe K, Sakazawa T, Yumoto E, Shibata K, Asahina M, lino M. Jasmonoyl-L-isoleucine is required for the 
production of a flavonoid phytoalexin but not diterpenoid phytoalexins in ultraviolet-irradiated rice leaves. Biosci Biotechnol Biochem. 2016;80(10):1934-8.

20. Rakwal R, Tamogami S, Kodama O. Role of jasmonic acid as a signaling molecule in copper chloride-elicited rice phytoalexin production. Biosci Biotechnol Biochem. 1996;60(6):1046-8.

21. Farrell KC, Jahan MA, Kovinich N. Distinct mechanisms of biotic and chemical elicitors enable additive elicitation of the anticancer Phytoalexin Glyceollin I. Molecules. 2017;22(8):1261-73.

22. Beyer EM. A potent inhibitor of ethylene action in plants. Plant Physiol. 1976;58(3):268-71.

23. Park D, Landini S, Graham M, Graham T. Induced distal defence potentiation against Phytophthora sojae in soybean. Physiol Mol Plant Pathol. 2002;60(6): 293-310.

24. Epperlein M, Noronha-Dutra A, Strange R. Involvement of the hydroxyl radical in the abiotic elicitation of phytoalexins in legumes. Physiol Mol Plant Pathol. 1986;28(1):67-77.

25. Qiu JL, Fiil BK, Petersen K, Nielsen HB, Botanga CJ, Thorgrimsen S, Palma K, Suarez-Rodriguez MC, Sandbech-Clausen S, Lichota J. Arabidopsis MAP kinase 4 regulates gene expression through transcription factor release in the nucleus. EMBO J. 2008;27(16):2214-21.

26. Höll J, Vannozzi A, Czemmel S, D'Onofrio C, Walker AR, Rausch T, Lucchin M, Boss PK, Dry IB, Bogs J. The R2R3-MYB transcription factors MYB14 and MYB15 regulate stilbene biosynthesis in Vitis vinifera. Plant Cell. 2013;25(10):4135-49.

27. Chen Y, Chen Z, Kang J, Kang D, Gu H, Qin G. AtMYB14 regulates cold tolerance in Arabidopsis. Plant Mol Biol Report. 2013;31(1):87-97.

28. Chezem WR, Memon A, Li F-S, Weng J-K, Clay NK. SG2-type R2R3-MYB transcription factor MYB15 controls defense-induced lignification and basal immunity in Arabidopsis. Plant Cell. 2017;29(8):1907-26.

29. Frerigmann H, Glawischnig E, Gigolashvili T. The role of MYB34, MYB51 and MYB122 in the regulation of camalexin biosynthesis in Arabidopsis thaliana. Front Plant Sci. 2015;6:654.

30. Dobin A, Davis CA, Schlesinger F, Drenkow J, Zaleski C, Jha S, Batut P, Chaisson M, Gingeras TR. STAR: ultrafast universal RNA-seq aligner. Bioinformatics. 2013;29(1):15-21.

31. Liao Y, Smyth GK, Shi W. featureCounts: an efficient general purpose program for assigning sequence reads to genomic features. Bioinformatics. 2013;30(7):923-30.

32. Anders $\mathrm{S}$, Huber W. Differential expression analysis for sequence count data. Genome Biol. 2010;11(10):R106.

33. Jacobs TB, LaFayette PR, Schmitz RJ, Parrott WA. Targeted genome modifications in soybean with CRISPR/Cas9. BMC Biotechnol. 2015;15(1):16.

34. Yang F, Ouma W, Li W, Doseff A, Grotewold E: Establishing the architecture of plant gene regulatory networks. In: Methods Enzymol vol. 576: Elsevier; 2016: 251-304.

35. Bhattacharyya M, Ward E. Resistance, susceptibility and accumulation of glyceollins I-III in soybean organs inoculated with Phytophthora megasperma f. Sp. glycinea. Physiol Mol Plant Pathol. 1986;29(2):227-37.

36. Akashi T, Aoki T, Ayabe S-i. Molecular and biochemical characterization of 2hydroxyisoflavanone dehydratase. Involvement of carboxylesterase-like proteins in leguminous isoflavone biosynthesis. Plant Physiol. 2005;137(3):882-91.

37. Akashi T, Sasaki K, Aoki T, Ayabe S-i, Yazaki K. Molecular cloning and characterization of a cDNA for pterocarpan 4-dimethylallyltransferase catalyzing the key prenylation step in the biosynthesis of glyceollin, a soybean phytoalexin. Plant physiology. 2009;149(2):683-93.

38. Yoneyama K, Akashi T, Aoki T. Molecular characterization of soybean Pterocarpan 2-Dimethylallyltransferase in Glyceollin biosynthesis: local gene and Whole-genome duplications of Prenyltransferase genes led to the structural diversity of soybean Prenylated Isoflavonoids. Plant Cell Physiol. 2016;57(12):2497-509.

39. Chu S, Wang J, Zhu Y, Liu S, Zhou X, Zhang H, C-e W, Yang W, Tian Z, Cheng H. An R2R3-type MYB transcription factor, GmMYB29, regulates isoflavone biosynthesis in soybean. PLoS Genet. 2017;13(5):e1006770.

40. Zhao M, Wang T, Wu P, Guo W, Su L, Wang Y, Liu Y, Yan F, Wang Q. Isolation and characterization of GmMYBJ3, an R2R3-MYB transcription factor that affects isoflavonoids biosynthesis in soybean. PLoS One. 2017;12(6):e0179990.

41. Yi J, Derynck MR, Li X, Telmer P, Marsolais F, Dhaubhadel S. A single-repeat MYB transcription factor, GmMYB176, regulates CHS8 gene expression and affects isoflavonoid biosynthesis in soybean. Plant J. 2010;62(6):1019-34.

42. Mainali HR, Vadivel AKA, Li X, Gijzen M, Dhaubhadel S. Soybean cyclophilin GmCYP1 interacts with an isoflavonoid regulator GmMYB176. Sci Rep. 2017;7:39550
43. Mishina TE, Zeier J. The Arabidopsis flavin-dependent monooxygenase FMO1 is an essential component of biologically induced systemic acquired resistance. Plant Physiol. 2006;141(4):1666-75.

44. Návarová H, Bernsdorff F, Döring A-C, Zeier J. Pipecolic acid, an endogenous mediator of defense amplification and priming, is a critical regulator of inducible plant immunity. Plant Cell. 2012;24(12):5123-41.

45. Song JT, Lu H, Greenberg JT. Divergent roles in Arabidopsis thaliana development and defense of two homologous genes, aberrant growth and death2 and AGD2-LIKE DEFENSE RESPONSE PROTEIN1, encoding novel aminotransferases. Plant Cell. 2004;16(2):353-66.

46. Hartmann M, Zeier T, Bernsdorff F, Reichel-Deland V, Kim D, Hohmann M, Scholten N, Schuck S, Bräutigam A, Hölzel T. Flavin monooxygenasegenerated $\mathrm{N}$-hydroxypipecolic acid is a critical element of plant systemic immunity. Cell. 2018;173(2):456-69 e416.

47. Bernsdorff F, Döring A-C, Gruner K, Schuck S, Bräutigam A, Zeier J. Pipecolic acid orchestrates plant systemic acquired resistance and defense priming via salicylic acid-dependent and-independent pathways. Plant Cell. 2016;28(1):102-29.

48. Ferrari S, Plotnikova JM, De Lorenzo G, Ausubel FM. Arabidopsis local resistance to Botrytis cinerea involves salicylic acid and camalexin and requires EDS4 and PAD2, but not SID2, EDS5 or PAD4. Plant J. 2003;35(2): 193-205.

49. Lai Z, Li Y, Wang F, Cheng Y, Fan B, Yu J-Q, Chen Z. Arabidopsis sigma factor binding proteins are activators of the WRKY33 transcription factor in plant defense. Plant Cell. 2011;23(10):3824-41.

50. Toth Z, Winterhagen P, Kalapos B, Su Y, Kovacs L, Kiss E. Expression of a grapevine NAC transcription factor gene is induced in response to powdery mildew colonization in salicylic acid-independent manner. Sci Rep. 2016;6:30825.

51. Thirumalaikumar VP, Devkar V, Mehterov N, Ali S, Ozgur R, Turkan I, MuellerRoeber B, Balazadeh S. NAC transcription factor JUNGBRUNNEN1 enhances drought tolerance in tomato. Plant Biotechnol J. 2017.

52. Yang Y, Zhu K, Wu J, Liu L, Sun G, He Y, Chen F, Yu D. identification and characterization of a novel NAC. Plant Cell Rep. 2016;35(8):1783-98.

53. Odell JT, Nagy F, Chua N-H. Identification of DNA sequences required for activity of the cauliflower mosaic virus 35 S promoter. Nature. 1985; 313(6005):810

54. Akashi T, Aoki T, Ayabe S-i. CYP81E1, a cytochrome P450 cDNA of licorice (Glycyrrhiza echinataL.), encodes Isoflavone 2'-hydroxylase. Biochem Biophys Res Commun. 1998;251(1):67-70.

55. Mao G, Meng X, Liu Y, Zheng Z, Chen Z, Zhang S. Phosphorylation of a WRKY transcription factor by two pathogen-responsive MAPKs drives phytoalexin biosynthesis in Arabidopsis. Plant Cell. 2011;23(4):1639-53.

56. McLellan H, Boevink PC, Armstrong MR, Pritchard L, Gomez S, Morales J, Whisson SC, Beynon JL, Birch PR. An RxLR effector from Phytophthora infestans prevents re-localisation of two plant NAC transcription factors from the endoplasmic reticulum to the nucleus. PLoS Pathog. 2013;9(10): e1003670.

57. Graham T, Graham M. Glyceollin elicitors induce major but distinctly different shifts in isoflavonoid metabolism in proximal and distal soybean cell populations. Mol Plant-Microbe Interact. 1991;4:60-8.

58. Subramanian S, Graham MY, Yu O, Graham TL. RNA interference of soybean isoflavone synthase genes leads to silencing in tissues distal to the transformation site and to enhanced susceptibility to Phytophthora sojae. Plant Physiol. 2005;137(4):1345-53.

59. Landini S, Graham MY, Graham TL. Lactofen induces isoflavone accumulation and glyceollin elicitation competency in soybean. Phytochemistry. 2003;62(6): 865-74.

60. Dann E, Diers B, Hammerschmidt R. Suppression of Sclerotinia stem rot of soybean by lactofen herbicide treatment. Phytopathology. 1999;89(7):598-602.

61. Graham T, Kim J, Graham M. Role of constitutive isoflavone conjugates in the accumulation of glyceollin in soybean infected with Phytophthora megasperma. Mol Plant-Microbe Interact. 1990;3:157-66.

62. Keen N. Specific elicitors of plant phytoalexin production: detenninants of race specificity in pathogens? Science. 1975;187(4171):74-5.

63. Klarman WL, Gerdemann JW. Resistance of soybeans to three Phytophthora species due to the production of a phytoalexin. Phytopathology. 1963;53: 1317-20.

64. Yoshikawa M, Masago H: Biochemical mechanism of glyceollin accumulation in soybean. Plant infection: the physiological and biochemical basis/edited by Yasuji Asada[et al] 1982. 
65. Lager I, Andréasson O, Dunbar TL, Andreasson E, Escobar MA, Rasmusson AG Changes in external pH rapidly alter plant gene expression and modulate auxin and elicitor responses. Plant Cell Environ. 2010;33(9):1513-28.

66. Ma Z, Song T, Zhu L, Ye W, Wang Y, Shao Y, Dong S, Zhang Z, Dou D, Zheng X. A Phytophthora sojae glycoside hydrolase 12 protein is a major virulence factor during soybean infection and is recognized as a PAMP. Plant Cell. 2015;27(7):2057-72.

67. Vishwakarma K, Upadhyay N, Singh J, Liu S, Singh VP, Prasad SM, Chauhan DK, Tripathi DK, Sharma S. Differential phytotoxic impact of plant mediated silver nanoparticles (AgNPs) and silver nitrate (AgNO3) on Brassica sp. Front Plant Sci. 2017:8:1501.

68. Mewis I, Schreiner M, Nguyen CN, Krumbein A, Ulrichs C, Lohse M, Zrenner R. UV-B irradiation changes specifically the secondary metabolite profile in broccoli sprouts: induced signaling overlaps with defense response to biotic stressors. Plant Cell Physiol. 2012:53(9):1546-60

69. Song $\mathrm{H}, \mathrm{Xu}$ X, Wang H, Tao Y. Protein carbonylation in barley seedling roots caused by aluminum and proton toxicity is suppressed by salicylic acid. Russ J Plant Physiol. 2011;58(4):653-9.

70. Ivanov YV, Savochkin YV, Kuznetsov W. Effect of mineral composition and medium pH on scots pine tolerance to toxic effect of zinc ions. Russ J Plant Physiol. 2013;60(2):260-9.

71. Martins N, Gonçalves S, Romano A. Metabolism and aluminum accumulation in Plantago almogravensis and P. Algarbiensis in response to low pH and aluminum stress. Biol Plant. 2013;57(2):325-31.

72. Sawaki Y, luchi S, Kobayashi Y, Kobayashi Y, Ikka T, Sakurai N, Fujita M, Shinozaki K, Shibata D, Kobayashi M. STOP1 regulates multiple genes that protect Arabidopsis from proton and aluminum toxicities. Plant Physiol. 2009;150(1):281-94.

73. luchi S, Koyama H, luchi A, Kobayashi Y, Kitabayashi S, Kobayashi Y, Ikka T, Hirayama T, Shinozaki K, Kobayashi M. Zinc finger protein STOP1 is critical for proton tolerance in Arabidopsis and coregulates a key gene in aluminum tolerance. Proc Natl Acad Sci. 2007;104(23):9900-5.

74. Mora-Macías J, Ojeda-Rivera JO, Gutiérrez-Alanís D, Yong-Villalobos L, Oropeza-Aburto A, Raya-González J, Jiménez-Domínguez G, Chávez-Calvillo G, Rellán-Álvarez R, Herrera-Estrella L. Malate-dependent Fe accumulation is a critical checkpoint in the root developmental response to low phosphate. Proc Natl Acad Sci. 2017;114(17):E3563-72

75. Uno Y, Furihata T, Abe H, Yoshida R, Shinozaki K, Yamaguchi-Shinozaki K. Arabidopsis basic leucine zipper transcription factors involved in an abscisic acid-dependent signal transduction pathway under drought and highsalinity conditions. Proc Natl Acad Sci. 2000;97(21):11632-7.

76. Wu A, Allu AD, Garapati P, Siddiqui H, Dortay H, Zanor M-I, Asensi-Fabado MA, Munné-Bosch S, Antonio C, Tohge T: JUNGBRUNNEN1, a reactive oxygen species-responsive NAC transcription factor, regulates longevity in Arabidopsis. Plant Cell 2012:tpc. 111.090894.

Ready to submit your research? Choose BMC and benefit from:

- fast, convenient online submission

- thorough peer review by experienced researchers in your field

- rapid publication on acceptance

- support for research data, including large and complex data types

- gold Open Access which fosters wider collaboration and increased citations

- maximum visibility for your research: over $100 \mathrm{M}$ website views per year

At $\mathrm{BMC}$, research is always in progress.

Learn more biomedcentral.com/submissions 